\title{
Solution of Unit Commitment Problem Using Shuffled Frog Leaping Algorithm
}

\author{
Mrs. J. Mary Anita ${ }^{1}$, Dr. I. Jacob Raglend ${ }^{2}$, Dr. D. P. Kothari ${ }^{3}$ \\ ${ }^{1}$ (Research Scholar, Noorul Islam University, Thackalay, Tamil Nadu, India) \\ ${ }^{2}$ (Prof. Noorul Islam University, Thackalay, Tamil Nadu, India) \\ ${ }_{3}^{3}$ (General Director, Vindhya Group of Institutions, Indore, India)
}

\begin{abstract}
This paper presents a solution to Unit commitment (UC) of thermal units based on a new evolutionary algorithm known as Shuffled Frog Leaping Algorithm(SFLA). The integer coded algorithm is based on the behavior of group of frogs searching for a location that has the maximum amount of available food. This algorithm involves local search and shuffling process and these are repeated until a required convergence is reached. In this proposed method of SFLA for the UC problem, the scheduling variables are coded as integers, so that the minimum up/down time constraints can be handled directly. To verify the performance of the proposed algorithm it is applied to the IEEE 14, 30, 56,118 bus systems and 10, 20 unit systems for a one day scheduling period. The results obtained are quite encouraging for the Unit Commitment problem when compared with the existing methods. The algorithm and simulation are carried out using Matlab software.
\end{abstract}

Key words: SFLA ,Frogs, Unit Commitment

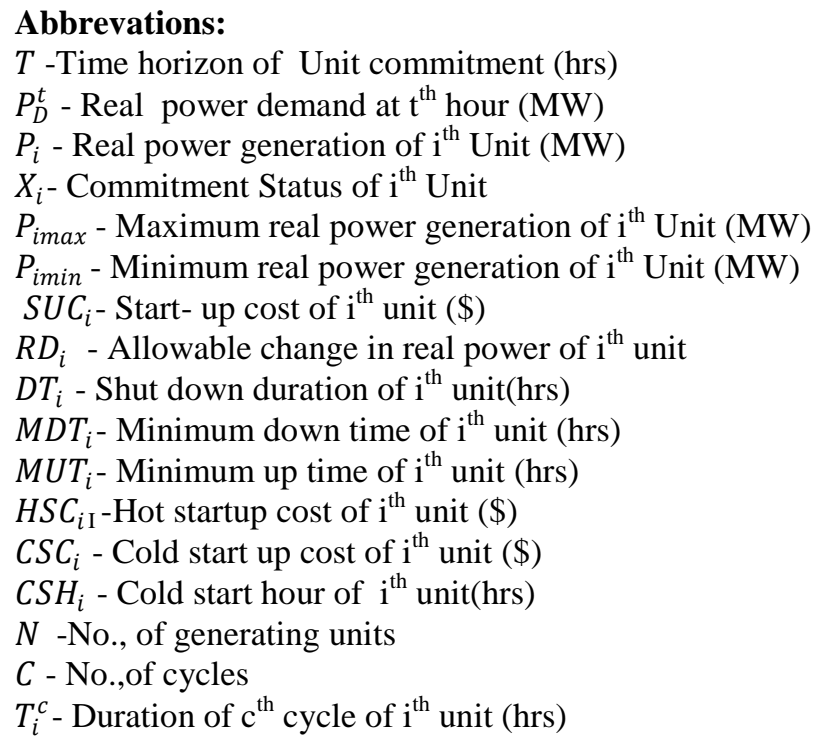

\section{INTRODUCTION}

Operating under the present competitive environment, Unit Commitment (UC) is essential since a significant amount of savings can be obtained by a sound UC decision. UC is a process of determining the minimal production cost generator turn ON/turn OFF schedule and real power outputs of committed units while meeting the forecasted demand over a scheduling horizon of usually between $24 \mathrm{hrs}$ to $168 \mathrm{hrs}$ ( 1 day- 7 days) .The obtained UC schedule should also satisfy the global constraints (power balance, spinning reserve and environmental) and local constraints like operational and physical constraints of every unit [1][2]\&[3]. Since it has to satisfy more number of constraints the UC Problem is a complex, non-linear, mixed integer optimization problem. UCP's combinatorial nature curtails any attempt to develop a rigorous mathematical optimization method.

Mathematical solution to UCP involves simultaneous solution of two sub problems. (i) The mixed integer non-linear programming problem of determining the generating units to be committed each hour of the planning horizon, while considering system capacity requirements. (ii)The quadratic programming problem of economic dispatch among the committed units during every specific hour of operation.

Complete enumeration can give an optimal solution but its excessive computational complexity has made it not suitable for large scale system. 
In Literature there exist more no of methods to solve UCP [4]. The available approaches may be (i) numerical solution techniques such as Priory List (PL), Dynamic programming (DP) [5], Lagrangian relaxation, Branch and bound, and MIP. The PL is simple and fast but always led to a solution of higher operating cost. DP suffers with the problem of sub optimal solution while truncating some of the non-feasible solution, to reduce its computational time.

LR [6] is modifiable to the model characteristics of specific utilities of power system. The constraints can be easily added to the main objective function but the major drawbacks are its sensitivity and the availability of dual optimal solution. (ii) The stochastic search methods such as Genetic Algorithm (GA), [7], [8]\&[9], Particle Swarm Optimization (PSO)[11], Ant colony optimization, and Bacterial foraging (BF)[13] . These methods are capable of handling complex nonlinear constraints to provide a high quality solution. GA suffers with long computation time due its random selection of GA operator. Integer coded GA for UC is more efficient than binary coded when accompanied by a suitable GA operator. Evolutionary programming (EP) differs from GA from the method of solution coding and selection of candidates for reproduction.

Eusuff and Lansey first introduced SFLA [14],[15]\&[16] in 2003. This method is based on the behavior of frogs search for the location that has the maximum amount of available food. Possible solutions are randomly generated to create the initial population of frogs. And these frogs are grouped into memeplexes. Memetic evolution step (local search) is carried out within every memeplex and a shuffling is done between the memeplexes. This process is repeated till a required convergence is reached. This algorithm has been successfully applied for several engineering optimization problems.

The integer coded UC [10] is used. The minimum up/down constraints are directly coded hence no need for any penalty function for these constraints. The performance of this algorithm is tested for a 10 unit system for a one day scheduling.

\section{MATHEMATICAL MODELING OF UC}

The total operating cost of electrical energy includes fuel cost, start up cost and shut down cost. The fuel costs are calculated using the data of unit heat rate \& fuel price information which is normally a quadratic equation of power output of each generator at each hour determined by Economic Dispatch(ED).

$$
F_{c}\left(P_{i}\right)=A_{i}+B_{i} P_{i}+C_{i} P_{i}^{2}
$$

Where, $\mathrm{A}_{\mathrm{i}}, \mathrm{B}_{\mathrm{i}}, \mathrm{C}_{\mathrm{i}}$ are coefficients of cost matrix.

The total fuel cost for the entire scheduling horizon ' $\mathrm{T}$ ' is given by

$$
T F C=\sum_{t-1}^{T} \sum_{i=1}^{N} F_{c} P_{i} * X_{i}(t)
$$

Where $X_{i}(t)$ is the status of $i^{\text {th }}$ unit at $t^{\text {th }}$.hour. Startup cost is the cost involved in bringing the thermal unit online. Start up costs are expressed as a function of the number of hours the units has been shut down. (exponential when cooling and linear when banking). Shut down costs are defined as a fixed amount for each unit/shutdown. However it is not taken into account in this paper. A simplified start up cost model is used as follows.

$$
S U C_{i}=\left\{\begin{array}{l}
H S C_{i}, \text { if } M D T_{i} \leq D T_{i}<M D T_{i}+C S H_{i} \\
C S C_{i}, \text { if } D T_{i}>M D T_{i}+C S H_{i}
\end{array}\right.
$$

$\mathrm{DT}_{\mathrm{i}}$ is the shut down duration, $\mathrm{MDT}_{\mathrm{i}}-$ Minimum down time, $\mathrm{HSC}_{\mathrm{i}}$-Hot startup cost, $\mathrm{CSC}_{\mathrm{i}}$ - Cold start up cost, and $\mathrm{CSH}_{\mathrm{i}}$ is the Cold start hour of $\mathrm{i}^{\text {th }}$ unit.

There are several constraints that must be satisfied by the UCP.

i) System power balance

The sum of generation of all the committed units at $\mathrm{t}^{\text {th }}$ hour must be greater than or equal to the demand at a particular hour ' $\mathrm{t}$ '.

$$
\sum_{i=1}^{N} X_{i}(t) P_{i}(t) \leq P_{D}(t), \quad t=1,2,3 \ldots \ldots . T
$$

ii) System spinning reserve requirements

In order to maintain certain degree of reliability an excess capacity of generation is essential to immediately take over when a running unit fails, or unexpected load occurs. A fixed reserve policy is used in this paper and a the mathematical equation is given by

iii) Min up/down time

$$
\sum_{i=1}^{N} X_{i}(t) P_{i}(t) \leq P_{D}(t) P_{R}(t), t=1,2,3 \ldots \ldots . T
$$

A committed unit can be turned off only after it satisfies its minimum up time values, at the same time, a reserved unit can be turned on only after it satisfies, its min down time. This is due to the fact that the temperature of a thermal unit can be increased or decreased only gradually. 


$$
\left\{\begin{array}{c}
T_{i}^{c} \geq M U T_{i} \text { if } T_{i}^{c}>0 \\
-T_{i}^{c} \geq M D T_{i} \text { if } T_{i}^{c}<0
\end{array}\right.
$$

where $T_{i}^{c}$ is a signed integer representing ON/OFF status duration of $c^{\text {th }}$ operating cycle of the $i^{\text {th }}$ unit . iv) Intial operating status of generating units

The initial operating status of every unit should take the last day's previous schedule into account, so that every unit satisfies it's minimum up/down time.

v) Maximum/Minimum power limits

Every unit has its own maximum/minimum power level of generation, beyond and below which it cannot generate.

\section{vi) Ramp rate constraints}

$$
P_{\text {imin }} \leq P_{i}^{t} \leq P_{\text {imax }}
$$

Since, the temperature of a thermal unit can only be increased or decreased gradually, the output also can be increased or decreased within a limit. The response rate constraints of the unit limits the power generation and is given by

Where $\tau=60 \mathrm{~min}$.

$$
\begin{aligned}
& P_{\text {imax }}(t)=\min \left(P_{\text {imax }}, P_{i(t-1)}+\tau R D_{i}\right) \\
& P_{\text {imin }}(t)=\max \left(P_{\text {imin }}, P_{i(t-1)}+\tau R D_{i}\right)
\end{aligned}
$$

\section{SHUFFLED FROG LEAPING ALGORITHM}

SFLA is a metaheuristic optimization method which combines the GA's memetic evolution and PSO's social behavior. It is a combination of deterministic and random strategies. The deterministic approach allows the algorithm to use the search space effectively to guide its heuristic search and the random approach ensures flexibility and robustness of the search process. SFLA mainly based on the behavior of group of frogs searching for the location that has the maximum amount of available food. This algorithm is capable of solving discrete and continuous optimization problems. It is also capable of solving non-linear non-differentiable, multi modal optimization problems. This algorithm has been successfully applied for several engineering applications like bridge deck repair, water source distribution, determination of optimal discrete pipe size for new pipe networks, data clustering, job shop scheduling etc, The most promising benefit of this algorithm is its faster convergence speed.

The SFLA involves a population of possible solutions defined by a set of virtual frogs. This set of virtual frogs is partitioned into subsets know as memeplexes. The memeplexes can be perceived as a set of parallel frog cultures attempting to reach some goal. Frog leaping improves an individual frog and enhances its performance towards the goal. Within each memeplex each frog holds different ideas and the idea of each frog can be used to infect the ideas of other frogs.

The process of passing information between the frogs of a memeplex is known as local search or memetic evolution step. After a defined number of memetic evolution step the virtual frogs are shuffled and reorganized so that the quality of memeplex is improved. Shuffling enhances the meme quality after infection and ensures the cultural evolution towards any particular interest. The process of memetic evolution and shuffling are repeated unit a required convergence is reached. This is given graphically in Fig.1. The following steps are involved in SFLA. 


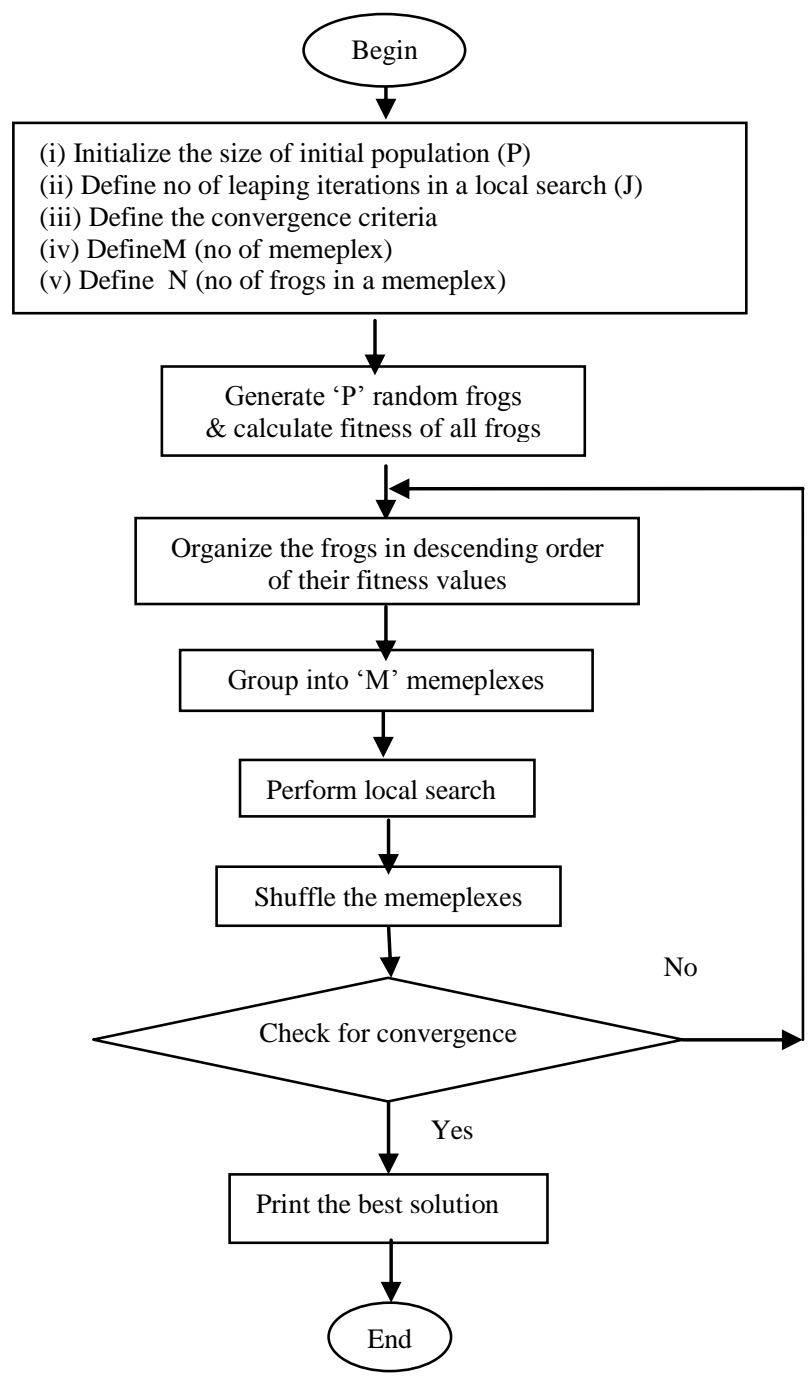

Fig(1) Flow Chart of SFLA

Step:I Formation of Initial population

1) Population size (no. of frogs )P is chosen

2) $P$ no. of frogs are generated randomly within the search space.

3) The position of every frog is defined as

$$
X_{i}=X_{i 1}, X_{i 2}, \ldots \ldots \ldots \ldots \ldots X_{i D}, \quad \text { Where } \mathrm{D} \text { is the no. of variables }
$$

4) The fitness of search frog is calculated as

$$
\text { fitnes }=\left\{\begin{array}{c}
1 / f(x)+c \text { for minimization problems } \\
f(x)+c \quad \text { for maximization problems }
\end{array}\right.
$$

$\mathrm{f}(\mathrm{x})$ is the objective function and $\mathrm{c}$ is a constant to ensure the fitness a positive value.

Step:II Grouping of Frogs into Memeplexes:

1) The frogs are sorted in descending order according to their fitness values.

2) The entire population of 'P' frogs are grouped into ' $M$ ' memeplexes, and each memeplex is formed so that each memeplex consists of ' $N$ ' no of frogs $(\mathrm{P}=\mathrm{MXN})$.

3)The partitioning of memeplexes is done so that each memeplex have frogs with lower and higher fitness values. For this the first frog goes to $1^{\text {st }}$ memeplex, the second frog goes to $2^{\text {nd }}$ memeplex, the $\mathrm{m}^{\text {th }}$ frog to $\mathrm{m}^{\text {th }}$ memeplex and $\mathrm{m}+1^{\text {th }}$ frog goes to $1^{\text {st }}$ memeplex. This procedure is illustrated in Fig.2. 


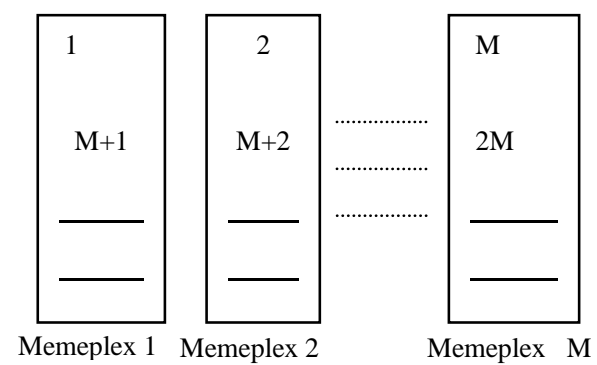

Fig. 2. Formation of Memeplexes

Step: III Local search process: (Memetic evolution step)

Within each memeplex, the frogs with worst $\left(\mathrm{X}_{\mathrm{w}}\right)$ \& best $\left(\mathrm{X}_{\mathrm{b}}\right)$ fitness values are identified. Also the frog with global fitness $X_{g}$ is also identified.

1) The frog with worst fitness is leaped towards the best frog by a random vector.

$$
\begin{aligned}
& D_{i}=\operatorname{rand}(1) *\left(X_{b}-X_{w}\right) \\
& \quad X_{w}=X_{w}+D_{i} \quad D_{\text {imin }}<\left|D_{i}\right|<D_{\text {imax }}
\end{aligned}
$$

2)The fitness of the new leaped worst frog is calculated. If there is no improvement in fitness, the leaping vector is calculated with $X_{\mathrm{g}}$

$$
\begin{aligned}
& D_{i}=\operatorname{rand}(1) *\left(X_{g}-X_{w}\right) \\
& \qquad X_{w}=X_{w}+D_{i} D_{\text {imin }}<\left|D_{i}\right|<D_{\text {imax }}
\end{aligned}
$$

3) The fitness of the new leaped worst frog is calculated. If there is no improvement, then $\mathrm{Xw}$ is replaced with a new random frog. This is illustrated in Fig. 3.

The steps 1, 2, 3, \& 4 are repeated for some specific number of iterations.

The entire process of local search is illustrated graphically in fig 4 . 


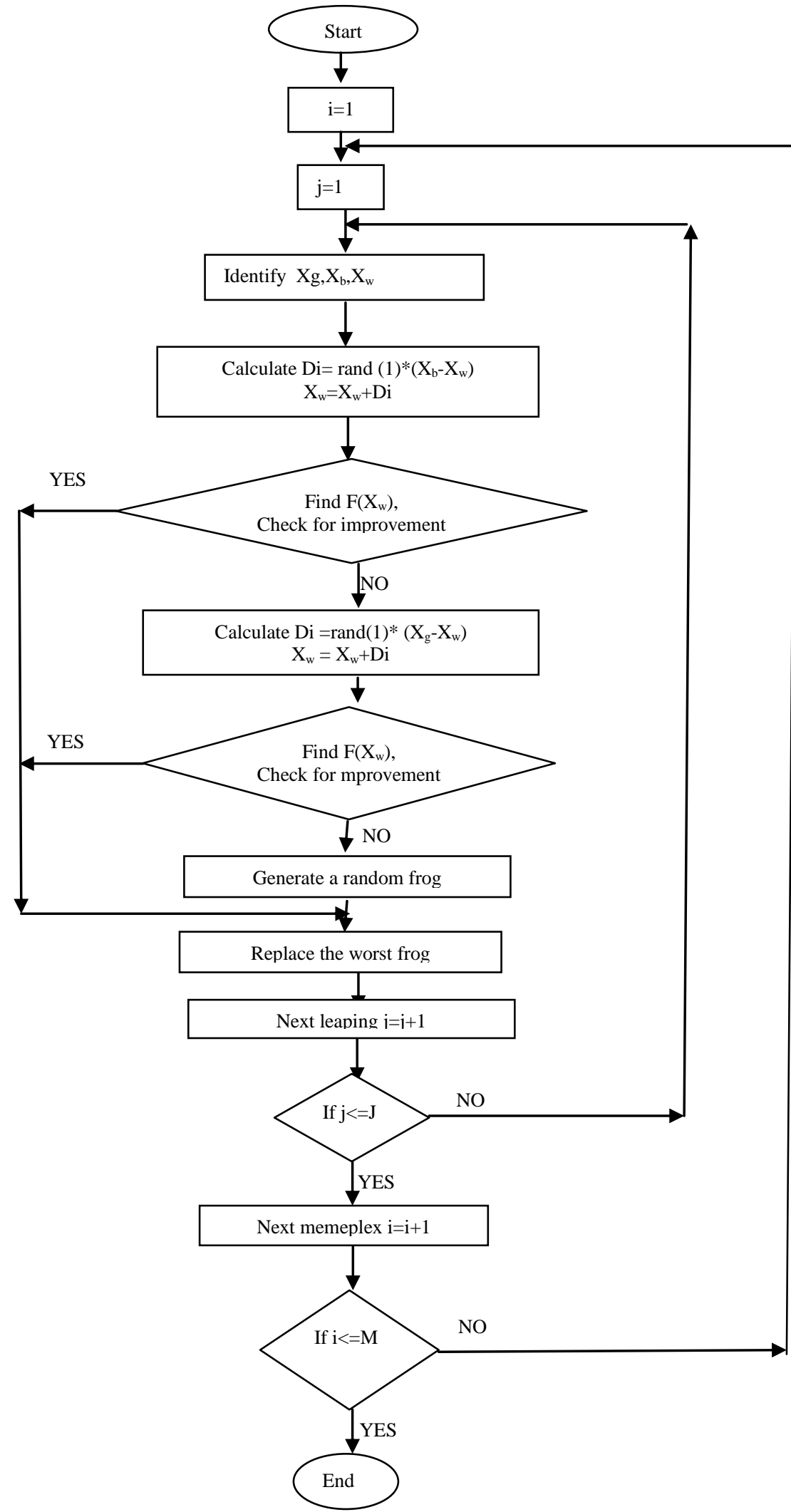

Fig.4. Local Search Process of Improved SFLA

Step: IV Shuffling Process:

After local search in every memeplex is completed shuffling of memeplex is done, and the frogs are reorganized in descending order of fitness values and again grouped into memeplex and local search process is carried out.

Step: V The above all steps I, II, III, IV are repeated until 
i) The relative change in the fitness of the global frog within a number of consecutive shuffling iterations is less than a pre-specified tolerance.

ii) The maximum predefined numbers of shuffling iterations have been reached.

\section{IMPLEMENTATION OF SFLA TO UCP}

\section{Definition of frog position}

The position of a frog in integer coded SFLA for UCP consists of a sequence of alternatively signed integers representing the duration of ON/OFF cycles of units during the scheduling horizon. A positive integer in the frog vector represents the duration of continuous ON state of a unit whereas the negative integer represents the duration of continuous OFF state of a unit. The size of a frog is decided by the no of units $(\mathrm{N})$ and no of cycles(C). No of cycles(C) is determined by the load peaks and minimum up and down time of units

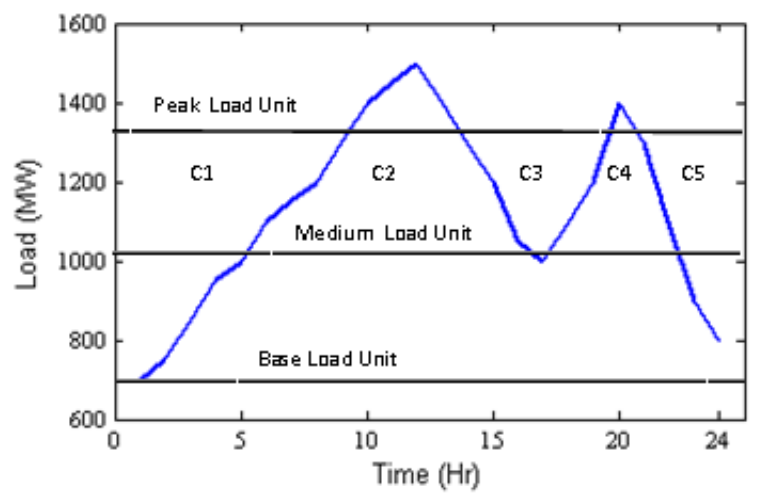

Fig(5) Load Curve for $24 \mathrm{Hrs}$

In this paper the load profile with two load peaks fig(3) is considered. From the figure it is understood that the peak units will have 5 cycles and the base units and intermediate units will have $1 \& 3$ respectively. So, the no of cycles vary between 1 to 5 . But for simplicity and to increase the search space, the peaking unit cycles are taken for base and intermediate units snd their remaining cycles are assumed to be zero. For a 10 unit, 5 cycle system the size of the frog for a one day scheduling is 1X10X5.Definition of frog from ON/OFF cycle duration of units and the UC schedule is illustrated in table :1

\section{Creating Initial Population}

A part of a frog representing the operating schedule of a particular unit during the scheduling horizon should be formed such that $\sum_{c=1}^{C}\left|T_{i}^{C}\right|=T$.

The values of $T_{i}^{c}$ of the initial population is randomly generated as follows.

Formation of first cycle: $\left(T_{i}^{l}\right)$

$\mathrm{T}_{\mathrm{i}}{ }^{1}$ is selected so that the unit continues the operating mode(ON/OFF) of the last cycle of the previous day scheduling $\left(\mathrm{T}_{\mathrm{i}}^{0}\right)$ for at least as many hours required so that no units are violating its minimum up/down time values.

$T_{i}^{1}=\left\{\begin{array}{l}+\operatorname{rand}\left(\max \left(0, M U T_{i}-T_{i}^{0}\right), T\right) \text { if } T_{i}^{0}>0 \\ -\operatorname{rand}\left(\max \left(0, M D T_{i}+T_{i}^{0}\right), T\right) \text { if } T_{i}^{0}<0\end{array}\right.$

Formation of in between cycles $\left(T_{i}^{c}, 1<c<C\right)$

The cycles between the initial and last cycles are generated considering the units minimum up/down time, the scheduling horizon( $\mathrm{T}$ ) and the duration of previous cycles(i.e) duration of (c-1) prior cycles. If $\mathrm{T}_{\mathrm{i}}^{\mathrm{c}-1}<0$, indicates cycle ' $\mathrm{c}$ ' is positive and it represents an $\mathrm{ON}$ status of $\mathrm{i}^{\text {th }}$ unit.

$$
T_{i}^{c}=\left\{\begin{array}{l}
+\operatorname{rand}\left(M U T_{i}, R T_{i}^{c-1}\right), \text { if }\left(R T_{i}^{c-1}>M U T_{i}\right) \\
+R T_{i}^{c-1}, \text { otherwise }
\end{array}\right.
$$

If $T_{i}^{c-1}>0$, indicates cycle 'c' is negative and it represents an OFF status of $\mathrm{i}^{\text {th }}$ unit. 


$$
T_{i}^{c}=\left\{\begin{array}{l}
-\operatorname{rand}\left(M D T_{i}, R T_{i}^{c-1}\right), \text { if }\left(R T_{i}^{c-1}>M D T_{i}\right) \\
-R T_{i}^{c-1}, \text { otherwise }
\end{array}\right.
$$

Where, $\mathrm{RT}_{\mathrm{i}}^{\mathrm{c}-1}$ indicates the remaining scheduling period after allocating the first (c-1) cycles.

$$
R T_{i}^{c-1}=T-\sum_{p=1}^{c-1}\left|T_{i}^{p}\right|
$$

Formation of last cycle $\left(T_{i}^{C}\right)$

The duration of last cycle ' $\mathrm{C}$ ' is decided by the duration of C-1 prior cycles (i.e) $T_{i}^{C}=R T_{i}^{C-1}$. If due to random generation of cycle duration the entire scheduling interval $(\mathrm{T})$ is completed within the first few cycles ' $\mathrm{c}$ ' $<\mathrm{C}$ then the remaining $\mathrm{c}+1 \ldots . . \mathrm{C}$ cycles are assigned to Zero. From this type of representation it is well known that the minimum up / down time constraint is satisfied in the coding stage itself and hence there is no need for any penalty function for this constraint in the objective function.

\section{Leaping of worst solution}

After formation of memeplex, the local search process is carried out in each memeplex. Leaping of worst frog towards the best frog is done by the random vector $D_{i}=\operatorname{rand}(1) *\left(X_{b}-X_{w}\right)$ or by $D_{i}=$ $\operatorname{rand}(1) *\left(X_{g}-X_{w}\right)$. Addition of this vector to the $X_{w}$ may lead to change in $X_{w}$ and it needs the following modifications.

i) Now, the sum of all $T_{i}^{c}$ of unit ' $i$ ' will not be equal to ' $T$ '. To adjust the following correction is done.

$$
\left(T_{i}^{1}, T_{i}^{2}, \ldots . . T_{i}^{C}\right)=\frac{T \cdot *\left(T_{i}^{1}, T_{i}^{2}, \ldots \ldots T_{i}^{C}\right), i=1,2, \ldots . N}{\sum_{k=1}^{C}\left|T_{i}^{k}\right|}
$$

(ii) The rand (1) function generates a random number between 0 and 1 the parameter which is a noninteger number and this may lead the parameter of $X_{w}$ to a non-integer values. But $X_{w}$ should be an integer vector. Hence to convert the non integer parameters of $X_{w}$ to integer the following correction is done by

$$
X_{\mathrm{w}}{ }^{1}=\text { Round }\left(X_{\mathrm{w}}\right)
$$

(iii) The above round of correction may again lead to the sum not equal to ' $\mathrm{T}$ ' Hence to adjust the values of $T_{i}^{c}$, the last non-zero cycle is adjusted as follows,

$$
T_{i}^{l}=T-\sum_{k=1}^{l-1}\left|T_{i}^{k}\right|, i=1,2, \ldots . N
$$

(iv) After generation of new $X_{w}$, the minimum up / down time should be adjusted so that there is no violation in this constraint. to ' $\mathrm{T}$ '

The correction in 'c' cycle should be followed by correction in ' $c+1$ ' cycle for adjusting the sum of $\mathrm{T}_{\mathrm{i}}^{\mathrm{c}}$

For $\mathrm{Ti}^{1}>0$ if $\mathrm{Ti}^{1}<\max \left(0, \mathrm{MUT}_{\mathrm{i}}-\mathrm{T}_{\mathrm{i}}{ }^{0}\right)$, then the duration of cycle $1 \&$ cycle 2 of unit ' $\mathrm{i}$ ' are changed as

$$
\left\{\begin{array}{c}
T_{i}^{2}=T_{i}^{2}-T_{i}^{1}+\max \left(0, M U T_{i}-T_{i}^{0}\right) \\
T_{i}^{1}=\max \left(0, M U T_{i}-T_{i}^{0}\right)
\end{array}\right.
$$

For $\mathrm{Ti}^{1}<0$ if $-\mathrm{Ti}^{1}<\max \left(0, \mathrm{MDT}_{\mathrm{i}}+\mathrm{T}_{\mathrm{i}}^{0}\right)$, then the duration of cycle $1 \&$ cycle 2 of unit ' $\mathrm{i}$ ' are changed

$$
\left\{\begin{array}{c}
T_{i}^{2}=T_{i}^{2}-T_{i}^{1}+\max \left(0, M D T_{i}+T_{i}^{0}\right) \\
T_{i}^{1}=-\max \left(0, M D T_{i}+T_{i}^{0}\right)
\end{array}\right.
$$

For $\mathrm{T}_{\mathrm{i}}^{\mathrm{c}}>0$ if $\mathrm{T}_{\mathrm{i}}^{\mathrm{c}}<\mathrm{MUT}_{\mathrm{i}}$ for $\mathrm{c}=2, \ldots . . \mathrm{C}-1$

the cycles ' $c$ ' and $\mathrm{c}+1$ of unit ' $\mathrm{i}$ ' are changed

$$
\left\{\begin{array}{l}
T_{i}^{c+1}=T_{i}^{c+1}-T_{i}^{c}+M U T_{i} \\
T_{i}^{c}=M U T_{i}
\end{array}\right.
$$

For $\mathrm{T}_{\mathrm{i}}^{\mathrm{c}}<0$ if $-\mathrm{T}_{\mathrm{i}}^{\mathrm{c}}<\mathrm{MDT}_{\mathrm{i}}$ for $\mathrm{c}=2 \ldots . . \mathrm{C}-1$ the cycles 'c' and $\mathrm{c}+1$ of unit ' $\mathrm{i}$ ' are changed

$$
\left\{\begin{array}{l}
T_{i}^{c+1}=T_{i}^{c+1}-T_{i}^{c}-M D T_{i} \\
T_{i}^{c}=M D T_{i}
\end{array}\right.
$$

After all the above corrections are carried out, on $X_{w}$, the Economic Dispatch (ED) should be carried out for each hour of scheduling horizon for all committed units. Then the fitness value is calculated. The sample frog is given in table: 1 


\section{Computation of fitness function}

The objective function of UC using SFLA has two terms, and they are the total operation cost and the penalty functions for violating system constraints (spinning reserve $\&$ power balance).

$$
T C=\sum_{t=1}^{T} \sum_{i=1}^{N} F C_{i}\left(P_{i}^{t}\right) * X_{i}(t)+S U_{T}+S D_{T}
$$

The penalty function has two terms. The first term for spinning reserve violation and is given by

$$
\prod_{\text {res }}=\omega \sum_{t=1}^{T} \frac{1}{D^{t}} R\left(\left(D^{t}+R^{t}\right)-\sum_{i=1}^{N} X_{i}(t) P_{\text {imax }}^{t}\right)
$$

the second term for excessive capacity is given by

$$
\prod_{\text {cap }}=\omega \sum_{t=1}^{T} \frac{1}{D^{t}} R\left(\sum_{i=1}^{N} X_{i}(t) P_{\text {imin }}^{t}-D^{t}\right)
$$

where ' $\omega$ ' depends on maximum operating cost of the system over a scheduling period ' $\mathrm{T}$ '

$$
\omega=\alpha \mathrm{T} \sum_{i=1}^{N} F C_{i}\left(P_{\text {imax }}\right) \text {, where } \alpha \text { is a constant. (26) }
$$

Now the objective is to minimize the fitness function

$$
\text { Fitness }=\mathrm{A} /\left(\mathrm{TC}+\Pi_{\text {res }}+\Pi_{\text {cap }}\right)
$$

\begin{tabular}{|c|c|c|c|c|c|}
\hline Unit & 1 & 2 & 3 & 4 & 5 \\
\hline \multirow[b]{2}{*}{1} & $\mathrm{~T}_{1}^{1}$ & $\mathrm{~T}_{1}^{2}$ & $\mathrm{~T}_{1}^{3}$ & $\mathrm{~T}_{1}^{4}$ & $\mathrm{~T}_{1}^{5}$ \\
\hline & 24 & 0 & 0 & 0 & 0 \\
\hline \multirow[b]{2}{*}{2} & $\mathrm{~T}_{2}^{1}$ & $\mathrm{~T}_{2}^{2}$ & $\mathrm{~T}_{2}^{3}$ & $\mathrm{~T}_{2}^{4}$ & $\mathrm{~T}_{2}^{5}$ \\
\hline & 24 & 0 & 0 & 0 & 0 \\
\hline \multirow[b]{2}{*}{3} & $\mathrm{~T}_{3}^{1}$ & $\mathrm{~T}_{3}^{2}$ & $\mathrm{~T}_{3}^{3}$ & $\mathrm{~T}_{3}^{4}$ & $\mathrm{~T}_{3}^{5}$ \\
\hline & -4 & 19 & -1 & 0 & 0 \\
\hline \multirow[b]{2}{*}{4} & $\mathrm{~T}_{4}^{1}$ & $\mathrm{~T}_{4}^{2}$ & $\mathrm{~T}_{4}^{3}$ & $\mathrm{~T}_{4}^{4}$ & $\mathrm{~T}_{4}^{5}$ \\
\hline & -5 & 17 & -2 & 0 & 0 \\
\hline \multirow[b]{2}{*}{5} & $\mathrm{~T}_{5}^{1}$ & $\mathrm{~T}_{5}^{2}$ & $\mathrm{~T}_{5}^{3}$ & $\mathrm{~T}_{5}^{4}$ & $\mathrm{~T}_{5}^{5}$ \\
\hline & 15 & -9 & 0 & 0 & 0 \\
\hline \multirow[b]{2}{*}{6} & $\mathrm{~T}_{6}^{1}$ & $\mathrm{~T}_{6}^{2}$ & $\mathrm{~T}_{6}^{3}$ & $\mathrm{~T}_{6}^{4}$ & $\mathrm{~T}_{6}^{5}$ \\
\hline & -8 & 6 & 4 & 3 & -3 \\
\hline \multirow[b]{2}{*}{7} & $\mathrm{~T}_{7}^{7}$ & $\mathrm{~T}_{7}^{2}$ & $\mathrm{~T}_{7}^{3}$ & $\mathrm{~T}_{7}^{4}$ & $\mathrm{~T}_{7}^{5}$ \\
\hline & -8 & 6 & -5 & 3 & -2 \\
\hline \multirow[b]{2}{*}{8} & $\mathrm{~T}_{8}^{1}$ & $\mathrm{~T}_{8}^{2}$ & $\mathrm{~T}_{8}^{3}$ & $\mathrm{~T}_{8}^{4}$ & $\mathrm{~T}_{8}^{5}$ \\
\hline & -9 & 4 & -6 & 1 & 4 \\
\hline \multirow{2}{*}{9} & $\mathrm{~T}_{9}^{1}$ & $\mathrm{~T}_{9}^{2}$ & $\mathrm{~T}_{9}^{3}$ & $\mathrm{~T}_{9}^{4}$ & $\mathrm{~T}_{9}^{5}$ \\
\hline & -10 & 2 & -12 & 0 & 0 \\
\hline \multirow[t]{2}{*}{10} & $\mathrm{~T}_{10}{ }^{1}$ & $\mathrm{~T}_{10}^{2}$ & $\mathrm{~T}_{10}^{3}$ & $\mathrm{~T}_{10}^{4}$ & $\mathrm{~T}_{10}^{5}$ \\
\hline & -11 & 1 & -12 & 0 & 0 \\
\hline
\end{tabular}

$\mathrm{A}=10^{8}$.A is a system dependent constant added for avoiding the fitness value from obtaining too small values. This should be of the order of the system maximum operating cost.

\section{TABLE:1 SAMPLE FROG FOR A 10 UNIT 5 CYCLE SYSTEM}

\section{SIMULATION RESULTS}

The performance of SFLA to UC has been tested for various test systems such as IEEE 14bus(5 units), IEEE 30bus(6 units), IEEE 56bus(7 units), IEEE 118bus(19 units), a standard a $10 \& 20$ unit systems for a one day scheduling. The generator and load data are given in appendix A \& B. The 10 unit system data is duplicated to obtain the 20 unit system data whereas the load data of 10 unit system is doubled for 20 unit system. The spinning reserve is assumed to be $10 \%$ of the load demand at each hour. The main parameters of SFLA have

\begin{tabular}{|c|c|c|c|c|c|c|c|c|c|c|c|c|c|c|c|c|c|c|c|c|c|c|c|c|}
\hline$\frac{\text { Unit }}{\text { Hour }}$ & 1 & 2 & 3 & 4 & 5 & 6 & 7 & 8 & 9 & 10 & 11 & 12 & 13 & 14 & 15 & 16 & 17 & 18 & 19 & 20 & 21 & 22 & 23 & 24 \\
\hline 1 & 1 & 1 & 1 & 1 & 1 & 1 & 1 & 1 & 1 & 1 & 1 & 1 & 1 & 1 & 1 & 1 & 1 & 1 & 1 & 1 & 1 & 1 & 1 & 1 \\
\hline 2 & 1 & 1 & 1 & 1 & 1 & 1 & 1 & 1 & 1 & 1 & 1 & 1 & 1 & 1 & 1 & 1 & 1 & 1 & 1 & 1 & 1 & 1 & 1 & 0 \\
\hline 4 & 0 & 0 & 0 & 0 & 0 & 0 & 0 & 0 & 0 & 0 & 0 & 0 & 0 & 1 & 1 & 1 & 1 & 1 & 1 & 1 & 1 & 0 & 0 & 0 \\
\hline 5 & 1 & 1 & 1 & 1 & 1 & 1 & 1 & 1 & 1 & 1 & 1 & 1 & 1 & 1 & 1 & 1 & 1 & 1 & 1 & 1 & 0 & 0 & 0 & 0 \\
\hline
\end{tabular}
been taken from paper [17]. SFLA[12] has an initial population of 200 frogs and a set of 20 memeplexes number of local search iteration is taken as 10. The SFLA program is developed and in MATLAB 2011'.

TABLE 2

UNIT COMMITMENT SCHEDULE OF 14 BUS SYSTEM (5 UNITS) FOR 24 HRS 
TABLE 3

UNIT COMMITMENT SCHEDULE OF 30 BUS SYSTEM (6 UNITS) FOR 24 HRS

\begin{tabular}{|c|c|c|c|c|c|c|c|c|c|c|c|c|c|c|c|c|c|c|c|c|c|c|c|c|}
\hline Unit & 1 & 2 & 3 & 4 & 5 & 6 & 7 & 8 & 9 & 10 & 11 & 12 & 13 & 14 & 15 & 16 & 17 & 18 & 19 & 20 & 21 & 22 & 23 & 24 \\
\hline Hour & & & & & & & & & & & & & & & & & & & & & & & \\
\hline 1 & 1 & 1 & 1 & 1 & 1 & 1 & 1 & 1 & 1 & 1 & 1 & 1 & 1 & 1 & 1 & 1 & 1 & 1 & 1 & 1 & 1 & 1 & 1 & 1 \\
\hline 2 & 1 & 1 & 1 & 1 & 1 & 1 & 1 & 1 & 1 & 1 & 1 & 1 & 1 & 1 & 1 & 1 & 1 & 1 & 1 & 1 & 1 & 1 & 0 & 0 \\
\hline 3 & 1 & 1 & 1 & 1 & 1 & 1 & 1 & 1 & 1 & 1 & 1 & 1 & 1 & 1 & 1 & 1 & 1 & 1 & 1 & 1 & 1 & 0 & 0 & 0 \\
\hline 4 & 1 & 1 & 1 & 1 & 1 & 1 & 1 & 1 & 1 & 1 & 1 & 1 & 1 & 1 & 1 & 1 & 1 & 0 & 0 & 0 & 0 & 0 & 0 & 0 \\
\hline 5 & 0 & 0 & 0 & 0 & 0 & 0 & 0 & 0 & 0 & 0 & 0 & 0 & 0 & 0 & 0 & 0 & 0 & 1 & 1 & 1 & 1 & 1 & 1 & 0 \\
\hline 6 & 1 & 1 & 1 & 1 & 1 & 1 & 1 & 1 & 1 & 1 & 1 & 1 & 1 & 1 & 1 & 1 & 1 & 0 & 0 & 0 & 0 & 0 & 0 & 1 \\
\hline
\end{tabular}

TABLE 4

UNIT COMMITMENT SCHEDULE OF 56 BUS SYSTEM (7UNITS) FOR 24 HRS

\begin{tabular}{|c|c|c|c|c|c|c|c|c|c|c|c|c|c|c|c|c|c|c|c|c|c|c|c|c|}
\hline $\begin{array}{l}\text { Unit } \\
\text { Hour }\end{array}$ & 1 & 2 & 3 & 4 & 5 & 6 & 7 & 8 & 9 & 10 & 11 & 12 & 13 & 14 & 15 & 16 & 17 & 18 & 19 & 20 & 21 & 22 & 23 & 24 \\
\hline 1 & 1 & 1 & 1 & 1 & 1 & 1 & 1 & 1 & 1 & 1 & 1 & 1 & 1 & 1 & 1 & 1 & 1 & 1 & 1 & 1 & 1 & 1 & 1 & 1 \\
\hline 2 & 0 & 0 & 0 & 0 & 0 & 0 & 0 & 0 & 0 & 0 & 0 & 0 & 0 & 0 & 0 & 0 & 0 & 0 & 0 & 0 & 0 & 0 & 1 & 1 \\
\hline 3 & 1 & 1 & 1 & 1 & 1 & 1 & 1 & 1 & 1 & 1 & 1 & 1 & 0 & 0 & 0 & 0 & 0 & 0 & 1 & 1 & 1 & 1 & 0 & 0 \\
\hline 4 & 1 & 1 & 1 & 1 & 1 & 1 & 0 & 0 & 0 & 0 & 0 & 0 & 0 & 0 & 0 & 0 & 1 & 1 & 1 & 1 & 0 & 0 & 0 & 0 \\
\hline 5 & 1 & 1 & 1 & 1 & 1 & 1 & 1 & 1 & 1 & 1 & 1 & 1 & 1 & 1 & 1 & 1 & 1 & 1 & 1 & 0 & 0 & 1 & 1 & 1 \\
\hline 6 & 0 & 0 & 0 & 0 & 0 & 0 & 0 & 0 & 0 & 0 & 0 & 0 & 0 & 0 & 0 & 0 & 0 & 0 & 0 & 0 & 0 & 1 & 0 & 0 \\
\hline 7 & 1 & 1 & 1 & 1 & 1 & 1 & 1 & 1 & 1 & 1 & 0 & 0 & 0 & 1 & 1 & 1 & 1 & 1 & 1 & 1 & 1 & 1 & 0 & 0 \\
\hline
\end{tabular}

TABLE 5

UNIT COMMITMENT SCHEDULE OF 118 BUS SYSTEM (19UNITS) FOR 24 HRS

\begin{tabular}{|c|c|c|c|c|c|c|c|c|c|c|c|c|c|c|c|c|c|c|c|c|c|c|c|c|}
\hline Unit & 1 & 2 & 3 & 4 & 5 & 6 & 7 & 8 & 9 & 10 & 11 & 12 & 13 & 14 & 15 & 16 & 17 & 18 & 19 & 20 & 21 & 22 & 23 & 24 \\
\hline Hour & & & & & & & & & & & & & & & & & & & & & & & \\
\hline 1 & 1 & 1 & 1 & 1 & 1 & 1 & 1 & 1 & 1 & 1 & 1 & 1 & 1 & 1 & 1 & 1 & 1 & 1 & 1 & 1 & 1 & 1 & 1 & 1 \\
\hline 2 & 1 & 1 & 1 & 1 & 1 & 1 & 1 & 1 & 1 & 1 & 1 & 1 & 1 & 1 & 1 & 1 & 1 & 1 & 1 & 1 & 1 & 1 & 1 & 1 \\
\hline 3 & 1 & 1 & 1 & 1 & 1 & 1 & 1 & 1 & 1 & 1 & 1 & 1 & 1 & 1 & 1 & 1 & 1 & 1 & 1 & 1 & 1 & 1 & 1 & 1 \\
\hline 4 & 1 & 1 & 1 & 1 & 1 & 1 & 1 & 1 & 1 & 1 & 1 & 1 & 1 & 1 & 1 & 1 & 1 & 1 & 1 & 1 & 1 & 1 & 1 & 1 \\
\hline 5 & 1 & 1 & 1 & 1 & 1 & 1 & 1 & 1 & 1 & 1 & 1 & 1 & 1 & 1 & 1 & 1 & 1 & 1 & 1 & 1 & 1 & 1 & 0 & 1 \\
\hline 6 & 0 & 0 & 0 & 0 & 0 & 0 & 0 & 0 & 1 & 1 & 1 & 1 & 1 & 1 & 1 & 1 & 1 & 0 & 0 & 1 & 1 & 0 & 0 & 0 \\
\hline 7 & 0 & 0 & 0 & 0 & 0 & 0 & 0 & 0 & 0 & 1 & 1 & 1 & 1 & 1 & 1 & 1 & 1 & 1 & 0 & 0 & 0 & 1 & 1 & 1 \\
\hline 8 & 0 & 0 & 0 & 0 & 0 & 0 & 0 & 0 & 0 & 1 & 1 & 1 & 1 & 1 & 1 & 1 & 0 & 0 & 0 & 0 & 1 & 1 & 1 & 1 \\
\hline 9 & 0 & 0 & 0 & 0 & 0 & 0 & 0 & 0 & 0 & 0 & 0 & 1 & 1 & 1 & 1 & 0 & 0 & 0 & 0 & 0 & 0 & 0 & 0 & 1 \\
\hline 10 & 0 & 0 & 0 & 0 & 0 & 0 & 0 & 0 & 0 & 0 & 1 & 1 & 0 & 0 & 0 & 0 & 0 & 0 & 0 & 0 & 0 & 0 & 1 & 1 \\
\hline 11 & 1 & 1 & 1 & 1 & 1 & 1 & 1 & 1 & 1 & 1 & 1 & 1 & 1 & 1 & 1 & 1 & 1 & 1 & 1 & 1 & 1 & 1 & 1 & 1 \\
\hline 12 & 1 & 1 & 1 & 1 & 1 & 1 & 1 & 1 & 1 & 1 & 1 & 1 & 1 & 1 & 1 & 1 & 1 & 1 & 1 & 1 & 1 & 1 & 1 & 1 \\
\hline 13 & 1 & 1 & 1 & 1 & 1 & 1 & 1 & 1 & 1 & 1 & 1 & 1 & 1 & 1 & 1 & 1 & 1 & 1 & 1 & 1 & 1 & 1 & 1 & 1 \\
\hline 14 & 1 & 1 & 1 & 1 & 1 & 1 & 1 & 1 & 1 & 1 & 1 & 1 & 1 & 1 & 1 & 1 & 1 & 1 & 1 & 1 & 1 & 1 & 1 & 0 \\
\hline 15 & 0 & 0 & 0 & 0 & 0 & 1 & 1 & 1 & 1 & 1 & 1 & 1 & 1 & 1 & 1 & 1 & 1 & 1 & 1 & 1 & 1 & 1 & 1 & 0 \\
\hline 16 & 1 & 1 & 1 & 1 & 1 & 1 & 1 & 1 & 1 & 1 & 1 & 1 & 1 & 1 & 1 & 1 & 1 & 1 & 1 & 1 & 0 & 0 & 1 & 1 \\
\hline 17 & 0 & 0 & 0 & 0 & 0 & 0 & 0 & 1 & 1 & 1 & 1 & 1 & 1 & 1 & 0 & 0 & 0 & 0 & 0 & 0 & 1 & 1 & 1 & 0 \\
\hline 18 & 0 & 0 & 0 & 0 & 0 & 0 & 0 & 0 & 0 & 0 & 0 & 0 & 0 & 1 & 1 & 1 & 1 & 0 & 0 & 0 & 0 & 0 & 0 & 1 \\
\hline 19 & 0 & 0 & 0 & 0 & 0 & 0 & 0 & 0 & 0 & 0 & 0 & 0 & 0 & 0 & 1 & 1 & 0 & 0 & 0 & 0 & 0 & 0 & 0 & 1 \\
\hline
\end{tabular}

TABLE 6

UNIT COMMITMENT SCHEDULE OF 10UNIT SYSTEM FOR 24 HRS

\begin{tabular}{|c|c|c|c|c|c|c|c|c|c|c|c|c|c|c|c|c|c|c|c|c|c|c|c|c|}
\hline $\begin{array}{l}\text { Unit } \\
\text { Hour }\end{array}$ & 1 & 2 & 3 & 4 & 5 & 6 & 7 & 8 & 9 & 10 & 11 & 12 & 13 & 14 & 15 & 16 & 17 & 18 & 19 & 20 & 21 & 22 & 23 & 24 \\
\hline 1 & 1 & 1 & 1 & 1 & 1 & 1 & 1 & 1 & 1 & 1 & 1 & 1 & 1 & 1 & 1 & 1 & 1 & 1 & 1 & 1 & 1 & 1 & 1 & 1 \\
\hline 2 & 1 & 1 & 1 & 1 & 1 & 1 & 1 & 1 & 1 & 1 & 1 & 1 & 1 & 1 & 1 & 1 & 1 & 1 & 1 & 1 & 1 & 1 & 1 & 1 \\
\hline 3 & 0 & 0 & 0 & 0 & 1 & 1 & 1 & 1 & 1 & 1 & 1 & 1 & 1 & 1 & 1 & 1 & 1 & 1 & 1 & 1 & 1 & 1 & 1 & 0 \\
\hline 4 & 0 & 0 & 0 & 0 & 0 & 1 & 1 & 1 & 1 & 1 & 1 & 1 & 1 & 1 & 1 & 1 & 1 & 1 & 1 & 1 & 1 & 1 & 0 & 0 \\
\hline 5 & 1 & 1 & 1 & 1 & 1 & 1 & 1 & 1 & 1 & 1 & 1 & 1 & 1 & 1 & 1 & 0 & 0 & 0 & 1 & 1 & 0 & 0 & 0 & 0 \\
\hline 6 & 0 & 0 & 0 & 0 & 0 & 0 & 0 & 0 & 1 & 1 & 1 & 1 & 1 & 1 & 0 & 0 & 0 & 1 & 1 & 1 & 1 & 0 & 0 & 0 \\
\hline 7 & 0 & 0 & 0 & 0 & 0 & 0 & 0 & 0 & 1 & 1 & 1 & 1 & 1 & 1 & 0 & 0 & 0 & 0 & 0 & 1 & 1 & 1 & 0 & 0 \\
\hline 8 & 0 & 0 & 0 & 0 & 0 & 0 & 0 & 0 & 0 & 1 & 1 & 1 & 1 & 0 & 0 & 0 & 0 & 0 & 0 & 1 & 0 & 0 & 0 & 0 \\
\hline 9 & 0 & 0 & 0 & 0 & 0 & 0 & 0 & 0 & 0 & 0 & 1 & 1 & 0 & 0 & 0 & 0 & 0 & 0 & 0 & 0 & 0 & 0 & 0 & 0 \\
\hline 10 & 0 & 0 & 0 & 0 & 0 & 0 & 0 & 0 & 0 & 0 & 0 & 1 & 0 & 0 & 0 & 0 & 0 & 0 & 0 & 0 & 0 & 0 & 0 & 0 \\
\hline
\end{tabular}



TABLE 7

UNIT COMMITMENT SCHEDULE OF 20 UNIT SYSTEM FOR 24 HRS

\begin{tabular}{|c|c|c|c|c|c|c|c|c|c|c|c|c|c|c|c|c|c|c|c|c|c|c|c|c|}
\hline Unit & 1 & 2 & 3 & 4 & 5 & 6 & 7 & 8 & 9 & 10 & 11 & 12 & 13 & 14 & 15 & 16 & 17 & 18 & 19 & 20 & 21 & 22 & 23 & 24 \\
\cline { 1 - 5 } Hour & & & & & & & & & & & & & & & & & & & & & & & 1 & 1 \\
\hline 1 & 1 & 1 & 1 & 1 & 1 & 1 & 1 & 1 & 1 & 1 & 1 & 1 & 1 & 1 & 1 & 1 & 1 & 1 & 1 & 1 & 1 & 1 & 1 & 1 \\
\hline 2 & 1 & 1 & 1 & 1 & 1 & 1 & 1 & 1 & 1 & 1 & 1 & 1 & 1 & 1 & 1 & 1 & 1 & 1 & 1 & 1 & 1 & 1 & 1 & 1 \\
\hline 3 & 0 & 0 & 0 & 0 & 1 & 1 & 1 & 1 & 1 & 1 & 1 & 1 & 1 & 1 & 1 & 1 & 1 & 1 & 1 & 1 & 1 & 1 & 1 & 0 \\
\hline 4 & 0 & 0 & 0 & 0 & 0 & 0 & 0 & 1 & 1 & 1 & 1 & 1 & 1 & 1 & 1 & 1 & 1 & 1 & 1 & 1 & 1 & 1 & 1 & 0 \\
\hline 5 & 1 & 1 & 1 & 1 & 1 & 1 & 1 & 1 & 1 & 1 & 1 & 1 & 1 & 1 & 1 & 1 & 0 & 0 & 0 & 0 & 0 & 0 & 0 & 0 \\
\hline 6 & 0 & 0 & 0 & 0 & 0 & 0 & 0 & 0 & 1 & 1 & 1 & 1 & 1 & 1 & 0 & 0 & 0 & 0 & 1 & 1 & 1 & 0 & 0 & 0 \\
\hline 7 & 0 & 0 & 0 & 0 & 0 & 0 & 0 & 0 & 1 & 1 & 1 & 1 & 1 & 1 & 0 & 0 & 0 & 0 & 0 & 1 & 1 & 1 & 0 & 0 \\
\hline 8 & 0 & 0 & 0 & 0 & 0 & 0 & 0 & 0 & 0 & 1 & 1 & 1 & 1 & 0 & 0 & 0 & 0 & 0 & 0 & 1 & 1 & 0 & 0 & 0 \\
\hline 9 & 0 & 0 & 0 & 0 & 0 & 0 & 0 & 0 & 0 & 0 & 1 & 1 & 0 & 0 & 0 & 0 & 0 & 0 & 0 & 1 & 0 & 0 & 0 & 0 \\
\hline 10 & 0 & 0 & 0 & 0 & 0 & 0 & 0 & 0 & 0 & 0 & 0 & 1 & 0 & 0 & 0 & 0 & 0 & 0 & 0 & 1 & 0 & 0 & 0 & 0 \\
\hline 11 & 1 & 1 & 1 & 1 & 1 & 1 & 1 & 1 & 1 & 1 & 1 & 1 & 1 & 1 & 1 & 1 & 1 & 1 & 1 & 1 & 1 & 1 & 1 & 1 \\
\hline 12 & 1 & 1 & 1 & 1 & 1 & 1 & 1 & 1 & 1 & 1 & 1 & 1 & 1 & 1 & 1 & 1 & 1 & 1 & 1 & 1 & 1 & 1 & 1 & 1 \\
\hline 13 & 0 & 0 & 0 & 0 & 1 & 1 & 1 & 1 & 1 & 1 & 1 & 1 & 1 & 1 & 1 & 1 & 1 & 1 & 1 & 1 & 1 & 1 & 0 & 0 \\
\hline 14 & 0 & 0 & 0 & 0 & 0 & 1 & 1 & 1 & 1 & 1 & 1 & 1 & 1 & 1 & 1 & 1 & 1 & 1 & 1 & 1 & 1 & 0 & 0 & 0 \\
\hline 15 & 1 & 1 & 1 & 1 & 1 & 1 & 1 & 1 & 1 & 1 & 1 & 1 & 1 & 1 & 1 & 1 & 0 & 0 & 0 & 0 & 0 & 0 & 0 & 0 \\
\hline 16 & 0 & 0 & 0 & 0 & 0 & 0 & 0 & 0 & 1 & 1 & 1 & 1 & 1 & 1 & 0 & 0 & 0 & 0 & 1 & 1 & 1 & 0 & 0 & 0 \\
\hline 17 & 0 & 0 & 0 & 0 & 0 & 0 & 0 & 0 & 1 & 1 & 1 & 1 & 1 & 1 & 0 & 0 & 0 & 0 & 0 & 1 & 1 & 1 & 0 & 0 \\
\hline 18 & 0 & 0 & 0 & 0 & 0 & 0 & 0 & 0 & 0 & 1 & 1 & 1 & 1 & 0 & 0 & 0 & 0 & 0 & 0 & 1 & 0 & 0 & 0 & 0 \\
\hline 19 & 0 & 0 & 0 & 0 & 0 & 0 & 0 & 0 & 0 & 0 & 1 & 1 & 0 & 0 & 0 & 0 & 0 & 0 & 0 & 0 & 0 & 0 & 0 & 0 \\
\hline 20 & 0 & 0 & 0 & 0 & 0 & 0 & 0 & 0 & 0 & 0 & 0 & 1 & 0 & 0 & 0 & 0 & 0 & 0 & 0 & 0 & 0 & 0 & 0 & 0 \\
\hline
\end{tabular}

TABLE 8

GENERATOR SCHEDULE OF 14 BUS SYSTEM (5 UNITS) FOR 24 HRS

\begin{tabular}{|c|c|c|c|c|c|}
\hline \multirow{2}{*}{ Hour } & \multicolumn{5}{|c|}{ Power Generations of Units(MW) } \\
\cline { 2 - 6 } & 1 & 2 & 3 & 4 & 5 \\
\hline 1 & 96.4 & 26.6 & 15.0 & 0 & 10.0 \\
\hline 2 & 117.8 & 30.2 & 15 & 0 & 10.0 \\
\hline 3 & 156.7 & 37.0 & 16.3 & 0 & 10.0 \\
\hline 4 & 176.6 & 40.2 & 17.2 & 0 & 10.0 \\
\hline 5 & 189.0 & 42.2 & 17.8 & 0 & 10.0 \\
\hline 6 & 179.9 & 40.7 & 17.4 & 0 & 10.0 \\
\hline 7 & 162.5 & 37.9 & 16.6 & 0 & 10.0 \\
\hline 8 & 141.9 & 34.5 & 15.6 & 0 & 10.0 \\
\hline 9 & 120.3 & 30.7 & 15.0 & 0 & 10.0 \\
\hline 10 & 84.5 & 24.5 & 15.0 & 0 & 10.0 \\
\hline 11 & 55.0 & 20.0 & 15.0 & 0 & 10.0 \\
\hline 12 & 81.1 & 23.9 & 15.0 & 0 & 10.0 \\
\hline 13 & 104.1 & 27.9 & 15.0 & 0 & 10.0 \\
\hline 14 & 103.5 & 29.5 & 15.0 & 10.0 & 10.0 \\
\hline 15 & 126.2 & 33.5 & 15.3 & 10.0 & 10.0 \\
\hline 16 & 150.8 & 37.6 & 16.6 & 10.0 & 10.0 \\
\hline 17 & 166.6 & 40.2 & 17.2 & 10.0 & 10.0 \\
\hline 18 & 164.1 & 39.8 & 17.1 & 10.0 & 10.0 \\
\hline 19 & 155.0 & 38.3 & 16.7 & 10.0 & 10.0 \\
\hline 20 & 138.4 & 30.6 & 16.0 & 10.0 & 10.0 \\
\hline 21 & 120.3 & 30.7 & 15.0 & 0 & 0 \\
\hline 22 & 114.1 & 27.9 & 15.0 & 0 & 0 \\
\hline 23 & 110.9 & 27.1 & 0 & 0 & 0 \\
\hline 24 & 103.0 & 0 & 0 & 0 & 0 \\
\hline & & & & & \\
\hline
\end{tabular}


TABLE 9

GENERATOR SCHEDULE OF 30 BUS SYSTEM (6 UNITS) FOR 24 HRS

\begin{tabular}{|c|c|c|c|c|c|c|}
\hline \multirow{2}{*}{ Hour } & & \multicolumn{5}{|c|}{ Power Generations of Units(MW) } \\
\cline { 2 - 7 } & 1 & 2 & 3 & 4 & 5 & 6 \\
\hline 1 & 95.3 & 33.7 & 15.0 & 10.0 & 0 & 12.0 \\
\hline 2 & 119.0 & 38.6 & 16.4 & 10.0 & 0 & 12.0 \\
\hline 3 & 145.7 & 43.5 & 17.8 & 10.0 & 0 & 12.0 \\
\hline 4 & 177.9 & 48.0 & 19.1 & 10.0 & 0 & 12.0 \\
\hline 5 & 190.0 & 49.9 & 19.6 & 11.9 & 0 & 12.0 \\
\hline 6 & 182.2 & 48.6 & 19.2 & 10.0 & 0 & 12.0 \\
\hline 7 & 160.0 & 45.6 & 18.4 & 10.0 & 0 & 12.0 \\
\hline 8 & 132.8 & 41.1 & 17.1 & 10.0 & 0 & 12.0 \\
\hline 9 & 115.8 & 38.0 & 16.2 & 10.0 & 0 & 12.0 \\
\hline 10 & 91.1 & 32.9 & 15.0 & 10.0 & 0 & 12.0 \\
\hline 11 & 79.5 & 30.5 & 15.0 & 10.0 & 0 & 12.0 \\
\hline 12 & 90.3 & 32.7 & 15.0 & 10.0 & 0 & 12.0 \\
\hline 13 & 98.4 & 34.4 & 15.2 & 10.0 & 0 & 12.0 \\
\hline 14 & 110.2 & 36.9 & 15.9 & 10.0 & 0 & 12.0 \\
\hline 15 & 128.7 & 40.4 & 16.9 & 10.0 & 0 & 12.0 \\
\hline 16 & 148.1 & 44.0 & 17.9 & 10.0 & 0 & 12.0 \\
\hline 17 & 159.9 & 45.7 & 18.4 & 10.0 & 0 & 12.0 \\
\hline 18 & 167.4 & 45.3 & 18.3 & 0 & 10.0 & 0 \\
\hline 19 & 163.3 & 44.6 & 18.1 & 0 & 10.0 & 0 \\
\hline 20 & 154.4 & 42.9 & 17.6 & 0 & 10.0 & 0 \\
\hline 21 & 137.5 & 39.8 & 16.7 & 0 & 10.0 & 0 \\
\hline 22 & 133.1 & 38.9 & 0 & 0 & 10.0 & 0 \\
\hline 23 & 151.0 & 0 & 0 & 0 & 10.0 & 0 \\
\hline 24 & 119.0 & 0 & 0 & 0 & 0 & 12.0 \\
\hline & & & & & & \\
\hline
\end{tabular}

TABLE 10

GENERATOR SCHEDULE OF 56 BUS SYSTEM (7 UNITS) FOR 24 HRS

\begin{tabular}{|c|c|c|c|c|c|c|c|}
\hline Unit & \multirow{2}{*}{1} & \multirow{2}{*}{2} & \multirow{2}{*}{3} & \multirow{2}{*}{4} & \multirow{2}{*}{5} & \multirow{2}{*}{6} & \multirow{2}{*}{7} \\
\hline Hour & & & & & & & \\
\hline 1 & 234.9 & 0 & 20.0 & 10.0 & 230.5 & 0 & 44.6 \\
\hline 2 & 264.9 & 0 & 20.0 & 10.0 & 259.2 & 0 & 65.9 \\
\hline 3 & 576.0 & 0 & 20.0 & 10.0 & 318.0 & 0 & 30.0 \\
\hline 4 & 576.0 & 0 & 20.0 & 10.0 & 390.0 & 0 & 30.0 \\
\hline 5 & 576.0 & 0 & 20.0 & 10.0 & 366.0 & 0 & 30.0 \\
\hline 6 & 576.0 & 0 & 20.0 & 10.0 & 356.0 & 0 & 30.0 \\
\hline 7 & 409.2 & 0 & 20.0 & 0 & 387.4 & 0 & 161.4 \\
\hline 8 & 400.9 & 0 & 20.0 & 0 & 379.5 & 0 & 155.6 \\
\hline 9 & 395.7 & 0 & 20.0 & 0 & 374.5 & 0 & 151.8 \\
\hline 10 & 388.2 & 0 & 20.0 & 0 & 367.3 & 0 & 146.5 \\
\hline 11 & 576.0 & 0 & 20.0 & 0 & 306.0 & 0 & 0 \\
\hline 12 & 375.7 & 0 & 20.0 & 0 & 355.4 & 0 & 0 \\
\hline 13 & 344.5 & 0 & 0 & 0 & 306.5 & 0 & 0 \\
\hline 14 & 282.9 & 0 & 0 & 0 & 247.7 & 0 & 57.4 \\
\hline 15 & 288.2 & 0 & 0 & 0 & 252.7 & 0 & $61 . .1$ \\
\hline 16 & 350.4 & 0 & 0 & 0 & 312.2 & 0 & 105.4 \\
\hline 17 & 380.9 & 0 & 0 & 10.0 & 350.8 & 0 & 134.3 \\
\hline 18 & 376.1 & 0 & 0 & 10.0 & 346.2 & 0 & 130.7 \\
\hline 19 & 546.0 & 0 & 20.0 & 10.0 & 225.9 & 0 & 41.1 \\
\hline 20 & 362.0 & 0 & 20.0 & 10.0 & 0 & 0 & 410.0 \\
\hline 21 & 576.0 & 0 & 20.0 & 0 & 0 & 0 & 10.0 \\
\hline 22 & 295.7 & 0 & 20.0 & 0 & 288.5 & 10.0 & 87.8 \\
\hline 23 & 355.5 & 10.0 & 0 & 0 & 326.5 & 0 & 0 \\
\hline 24 & 331.4 & 10.0 & 0 & 0 & 303.6 & 0 & 0 \\
\hline
\end{tabular}


TABLE 11

GENERATOR SCHEDULE OF118 BUS SYSTEM (19 UNITS) FOR 24 HRS

\begin{tabular}{|c|c|c|c|c|c|c|c|c|c|c|c|c|c|c|c|c|c|c|c|}
\hline Unit & 1 & 2 & 3 & 4 & 5 & 6 & 7 & 8 & 9 & 10 & 11 & 12 & 13 & 14 & 15 & 16 & 17 & 18 & 19 \\
\hline Hour & & & & & & & & & & & & & & & & & & & \\
\hline 1 & 367.2 & 10.0 & 30.0 & 163.0 & 1.0 & 0 & 0 & 0 & 0 & 0 & 290.1 & 291.3 & 900.0 & 430.7 & 0 & 681.7 & 0 & 5.0 & 0 \\
\hline 2 & 372.9 & 10.0 & 30.0 & 167.3 & 1.0 & 0 & 0 & 0 & 0 & 0 & 295.3 & 296.5 & 900.0 & 436.80 & 0 & 685.0 & 0 & 5.0 & 0 \\
\hline 3 & 500.0 & 10.0 & 30.0 & 151.4 & 1.0 & 0 & 0 & 0 & 0 & 0 & 282.2 & 283.4 & 900.0 & 421.4 & 0 & 665.6 & 0 & 5.0 & 0 \\
\hline 4 & 500.0 & 10.0 & 30.0 & 77.7 & 1.0 & 0 & 0 & 0 & 0 & 0 & 400.0 & 400.0 & 900.0 & 317.3 & 0 & 659.0 & 0 & 5.0 & 0 \\
\hline 5 & 500.0 & 10.0 & 30.0 & 143.8 & 1.0 & 0 & 0 & 0 & 0 & 0 & 400.0 & 400.0 & 900.0 & 410.6 & 1.0 & 659.6 & 0 & 5.0 & 0 \\
\hline 6 & 500.0 & 10.0 & 30.0 & 134.0 & 1.0 & 0 & 0 & 0 & 0 & 0 & 400.0 & 400.0 & 900.0 & 600.0 & 1.0 & 659.0 & 0 & 5.0 & 0 \\
\hline 7 & 500.0 & 10.0 & 30.0 & 163.4 & 1.0 & 0 & 0 & 0 & 0 & 0 & 400.0 & 400.0 & 900.0 & 600.0 & 1.0 & 675.6 & 0 & 5.0 & 0 \\
\hline 8 & 500.0 & 10.0 & 30.0 & 110.3 & 1.0 & 0 & 0 & 0 & 0 & 0 & 400.0 & 400.0 & 900.0 & 593.7 & 1.0 & 659.0 & 30.0 & 5.0 & 0 \\
\hline 9 & 486.0 & 10.0 & 30.0 & 40.0 & 1.0 & 3.0 & 0 & 0 & 0 & 0 & 400.0 & 400.0 & 900.0 & 600.0 & 1.0 & 659.0 & 30.0 & 0 & 0 \\
\hline 10 & 500.0 & 10.0 & 30.0 & 40.0 & 1.0 & 3.0 & 30.0 & 5.0 & 0 & 0 & 400.0 & 400.0 & 900.0 & 600.0 & 1.0 & 490.0 & 30.0 & 0 & 0 \\
\hline 11 & 454.0 & 10.0 & 30.0 & 40.0 & 1.0 & 3.0 & 30.0 & 5.0 & 0 & 20.0 & 400.0 & 400.0 & 900.0 & 288.1 & 1.0 & 638.0 & 30.0 & 0 & 0 \\
\hline 12 & 404.0 & 10.0 & 30.0 & 40.0 & 1.0 & 3.0 & 30.0 & 5.0 & 20.0 & 20.0 & 400.0 & 400.0 & 900.0 & 258.8 & 1.0 & 647.2 & 30.0 & 0 & 0 \\
\hline 13 & 500.0 & 10.0 & 30.0 & 40.0 & 1.0 & 3.0 & 30.0 & 5.0 & 20.0 & 0 & 400.0 & 400.0 & 826.9 & 244.1 & 1.0 & 634.0 & 30.0 & 0 & 0 \\
\hline 14 & 500.0 & 10.0 & 30.0 & 40.0 & 1.0 & 3.0 & 30.0 & 5.0 & 20.0 & 0 & 400.0 & 400.0 & 900.0 & 600.0 & 1.0 & 235.0 & 30.0 & 5.0 & 0 \\
\hline 15 & 500.0 & 10.0 & 30.0 & 40.0 & 1.0 & 3.0 & 30.0 & 5.0 & 20.0 & 0 & 400.0 & 400.0 & 900.0 & 600.0 & 1.0 & 471.0 & 0 & 5.0 & 0 \\
\hline 16 & 500.0 & 10.0 & 30.0 & 72.0 & 1.0 & 3.0 & 30.0 & 5.0 & 0 & 0 & 400.0 & 400.0 & 900.0 & 600.0 & 1.0 & 659.0 & 0 & 5.0 & 0 \\
\hline 17 & 500.0 & 10.0 & 30.0 & 81.0 & 1.0 & 3.0 & 30.0 & 0 & 0 & 0 & 400.0 & 400.0 & 900.0 & 600.0 & 1.0 & 659.0 & 0 & 5.0 & 0 \\
\hline 18 & 500.0 & 10.0 & 30.0 & 184.6 & 1.0 & 0 & 30.0 & 0 & 0 & 0 & 400.0 & 400.0 & 872.6 & 462.6 & 1.0 & 688.2 & 0 & 5.0 & 0 \\
\hline 19 & 500.0 & 10.0 & 30.0 & 147.8 & 1.0 & 0 & 0 & 0 & 0 & 0 & 400.0 & 400.0 & 900.0 & 410.6 & 1.0 & 659.6 & 0 & 0 & 0 \\
\hline 20 & 185.0 & 10.0 & 30.0 & 40.0 & 1.0 & 3.0 & 0 & 0 & 0 & 0 & 400.0 & 400.0 & 900.0 & 600.0 & 1.0 & 700.0 & 0 & 0 & 0 \\
\hline 21 & 500.0 & 10.0 & 42.2 & 228.2 & 1.0 & 3.0 & 0 & 5.0 & 0 & 0 & 400.0 & 400.0 & 900.0 & 600.0 & 1.0 & 0.0 & 119.6 & 0 & 0 \\
\hline 22 & 500.0 & 10.0 & 30.0 & 201.3 & 1.0 & 0 & 30.0 & 5.0 & 0 & 0 & 400.0 & 400.0 & 894.3 & 584.0 & 1.0 & 0 & 96.4 & 0 & 0 \\
\hline 23 & 302.5 & 10.0 & 30.0 & 152.0 & 0 & 0 & 30.0 & 5.0 & 0 & 20.0 & 276.9 & 278.1 & 900.0 & 415.2 & 1.0 & 673.1 & 54.2 & 0 & 0 \\
\hline 24 & 500.0 & 10.0 & 30.0 & 176.1 & 1.0 & 0 & 30.0 & 5.0 & 20.0 & 20.0 & 400.0 & 400.0 & 878.2 & 0 & 0 & 686.7 & 0 & 5.0 & 4.0 \\
\hline
\end{tabular}

TABLE 12

GENERATOR SCHEDULE OF 10 UNIT SYSTEM FOR 24 HRS

\begin{tabular}{|c|c|c|c|c|c|c|c|c|c|c|}
\hline \multirow{2}{*}{ Hour } & \multicolumn{10}{|c|}{ Power Generations of Units(MW) } \\
\cline { 2 - 13 } & 1 & 2 & 3 & 4 & 5 & 6 & 7 & 8 & 9 & 10 \\
\hline 1 & 455 & 220 & 0 & 0 & 25 & 0 & 0 & 0 & 0 & 0 \\
\hline 2 & 455 & 270 & 0 & 0 & 25 & 0 & 0 & 0 & 0 & 0 \\
\hline 3 & 455 & 370 & 0 & 0 & 25 & 0 & 0 & 0 & 0 & 0 \\
\hline 4 & 455 & 455 & 0 & 0 & 40 & 0 & 0 & 0 & 0 & 0 \\
\hline 5 & 455 & 390 & 130 & 0 & 25 & 0 & 0 & 0 & 0 & 0 \\
\hline 6 & 455 & 360 & 130 & 130 & 25 & 0 & 0 & 0 & 0 & 0 \\
\hline 7 & 455 & 410 & 130 & 130 & 25 & 0 & 0 & 0 & 0 & 0 \\
\hline 8 & 455 & 455 & 130 & 130 & 30 & 0 & 0 & 0 & 0 & 0 \\
\hline 9 & 455 & 455 & 130 & 130 & 85 & 20 & 25 & 0 & 0 & 0 \\
\hline 10 & 455 & 455 & 130 & 130 & 162 & 33 & 25 & 10 & 0 & 0 \\
\hline 11 & 455 & 455 & 130 & 130 & 162 & 80 & 25 & 10 & 10 & 0 \\
\hline 12 & 455 & 455 & 130 & 130 & 162 & 80 & 58 & 10 & 10 & 10 \\
\hline 13 & 455 & 455 & 130 & 130 & 162 & 33 & 25 & 10 & 0 & 0 \\
\hline 14 & 455 & 455 & 130 & 130 & 85 & 20 & 25 & 0 & 0 & 0 \\
\hline 15 & 455 & 455 & 130 & 130 & 25 & 0 & 0 & 0 & 0 & 0 \\
\hline 16 & 455 & 335 & 130 & 130 & 0 & 0 & 0 & 0 & 0 & 0 \\
\hline 17 & 455 & 285 & 130 & 130 & 0 & 0 & 0 & 0 & 0 & 0 \\
\hline 18 & 455 & 365 & 130 & 130 & 0 & 20 & 0 & 0 & 0 & 0 \\
\hline 19 & 440 & 455 & 130 & 130 & 25 & 20 & 0 & 0 & 0 & 0 \\
\hline 20 & 455 & 455 & 130 & 130 & 162 & 33 & 25 & 10 & 0 & 0 \\
\hline 21 & 455 & 455 & 130 & 130 & 85 & 20 & 25 & 0 & 0 & 0 \\
\hline 22 & 455 & 455 & 130 & 35 & 0 & 0 & 25 & 0 & 0 & 0 \\
\hline 23 & 455 & 315 & 130 & 0 & 0 & 0 & 0 & 0 & 0 & 0 \\
\hline 24 & 455 & 345 & 0 & 0 & 0 & 0 & 0 & 0 & 0 & 0 \\
\hline
\end{tabular}


GENERATOR SCHEDULE OF 20 UNIT SYSTEM FOR 24 HRS

\begin{tabular}{|c|c|c|c|c|c|c|c|c|c|c|c|c|c|c|c|c|c|c|c|c|}
\hline \multirow{2}{*}{ Hour } & \multicolumn{20}{|c|}{ Power Generations of Units(MW) } \\
\hline & 1 & 2 & 3 & 4 & 5 & 6 & 7 & 8 & 9 & 10 & 11 & 12 & 13 & 14 & 15 & 16 & 17 & 18 & 19 & 20 \\
\hline 1 & 455 & 455 & 0 & 0 & 25 & 0 & 0 & 0 & 0 & 0 & 290 & 150 & 0 & 0 & 25 & 0 & 0 & 0 & 0 & 0 \\
\hline 2 & 455 & 455 & 0 & 0 & 25 & 0 & 0 & 0 & 0 & 0 & 390 & 150 & 0 & 0 & 25 & 0 & 0 & 0 & 0 & 0 \\
\hline 3 & 455 & 345 & 0 & 0 & 25 & 0 & 0 & 0 & 0 & 0 & 455 & 395 & 0 & 0 & 25 & 0 & 0 & 0 & 0 & 0 \\
\hline 4 & 455 & 455 & 0 & 0 & 40 & 0 & 0 & 0 & 0 & 0 & 455 & 455 & 0 & 0 & 25 & 0 & 0 & 0 & 0 & 0 \\
\hline 5 & 455 & 455 & 130 & 0 & 55 & 0 & 0 & 0 & 0 & 0 & 455 & 455 & 0 & 0 & 25 & 0 & 0 & 0 & 0 & 0 \\
\hline 6 & 455 & 400 & 130 & 130 & 25 & 0 & 0 & 0 & 0 & 0 & 455 & 450 & 130 & 0 & 25 & 0 & 0 & 0 & 0 & 0 \\
\hline 7 & 455 & 455 & 130 & 130 & 162 & 0 & 0 & 0 & 0 & 0 & 455 & 228 & 130 & 130 & 25 & 0 & 0 & 0 & 0 & 0 \\
\hline 8 & 455 & 455 & 130 & 130 & 35 & 0 & 0 & 0 & 0 & 0 & 455 & 455 & 130 & 130 & 25 & 0 & 0 & 0 & 0 & 0 \\
\hline 9 & 378 & 455 & 130 & 130 & 162 & 80 & 25 & 0 & 0 & 0 & 455 & 455 & 130 & 130 & 25 & 20 & 25 & 0 & 0 & 0 \\
\hline 10 & 453 & 455 & 130 & 130 & 162 & 80 & 85 & 55 & 0 & 0 & 455 & 455 & 130 & 130 & 25 & 20 & 25 & 10 & 0 & 0 \\
\hline 11 & 455 & 455 & 130 & 130 & 162 & 80 & 85 & 55 & 10 & 0 & 455 & 455 & 130 & 130 & 103 & 20 & 25 & 10 & 10 & 0 \\
\hline 12 & 455 & 455 & 130 & 130 & 162 & 80 & 85 & 55 & 55 & 55 & 455 & 455 & 130 & 130 & 93 & 20 & 25 & 10 & 10 & 10 \\
\hline 13 & 453 & 455 & 130 & 130 & 162 & 80 & 85 & 55 & 0 & 0 & 455 & 455 & 130 & 130 & 25 & 20 & 25 & 10 & 0 & 0 \\
\hline 14 & 378 & 455 & 130 & 130 & 162 & 80 & 25 & 0 & 0 & 0 & 455 & 455 & 130 & 130 & 25 & 20 & 25 & 0 & 0 & 0 \\
\hline 15 & 455 & 455 & 130 & 130 & 35 & 0 & 0 & 0 & 0 & 0 & 455 & 455 & 130 & 130 & 25 & 0 & 0 & 0 & 0 & 0 \\
\hline 16 & 455 & 455 & 130 & 130 & 0 & 0 & 0 & 0 & 0 & 0 & 455 & 215 & 130 & 130 & 0 & 0 & 0 & 0 & 0 & 0 \\
\hline 17 & 455 & 455 & 130 & 130 & 0 & 0 & 0 & 0 & 0 & 0 & 455 & 150 & 130 & 95 & 0 & 0 & 0 & 0 & 0 & 0 \\
\hline 18 & 455 & 455 & 130 & 130 & 0 & 80 & 0 & 0 & 0 & 0 & 455 & 215 & 130 & 130 & 0 & 20 & 0 & 0 & 0 & 0 \\
\hline 19 & 450 & 455 & 130 & 130 & 25 & 20 & 0 & 0 & 0 & 0 & 455 & 455 & 130 & 130 & 0 & 20 & 0 & 0 & 0 & 0 \\
\hline 20 & 401 & 455 & 130 & 130 & 162 & 80 & 25 & 10 & 10 & 10 & 455 & 455 & 130 & 130 & 162 & 20 & 25 & 10 & 0 & 0 \\
\hline 21 & 393 & 455 & 130 & 130 & 162 & 80 & 25 & 10 & 0 & 0 & 455 & 455 & 130 & 130 & 0 & 20 & 25 & 0 & 0 & 0 \\
\hline 22 & 265 & 455 & 130 & 130 & 0 & 0 & 25 & 0 & 0 & 0 & 455 & 455 & 130 & 130 & 0 & 0 & 25 & 0 & 0 & 0 \\
\hline 23 & 455 & 455 & 130 & 0 & 0 & 0 & 0 & 0 & 0 & 0 & 455 & 175 & 130 & 0 & 0 & 0 & 0 & 0 & 0 & 0 \\
\hline 24 & 455 & 455 & 0 & 0 & 0 & 0 & 0 & 0 & 0 & 0 & 455 & 235 & 0 & 0 & 0 & 0 & 0 & 0 & 0 & 0 \\
\hline
\end{tabular}

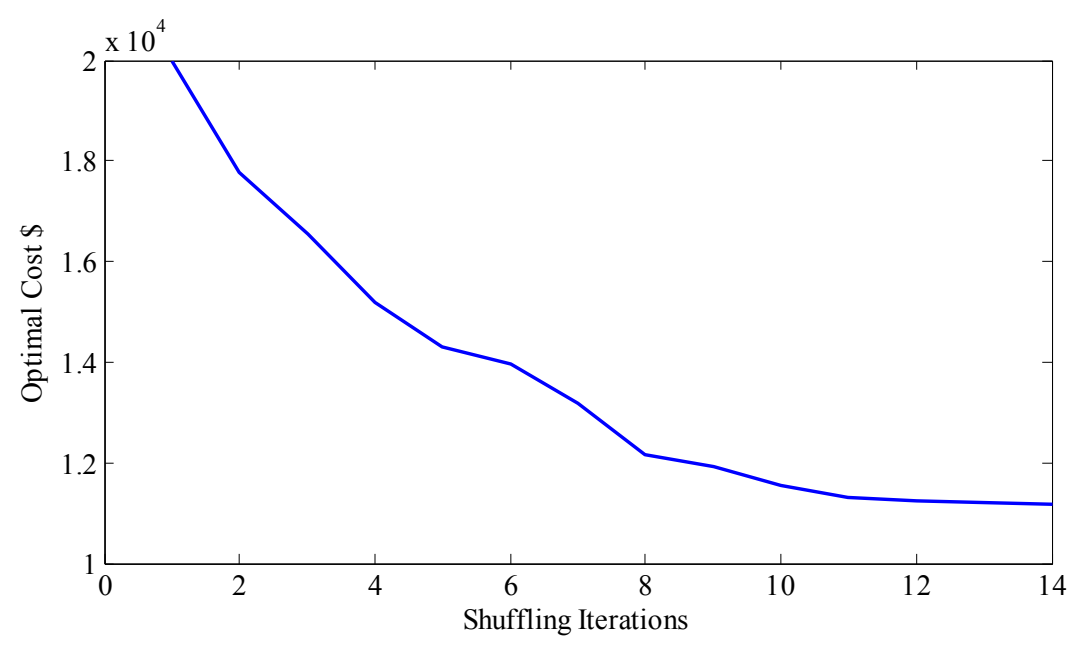

Fig(6) Convergence of SFLA for14Bus (5units) system

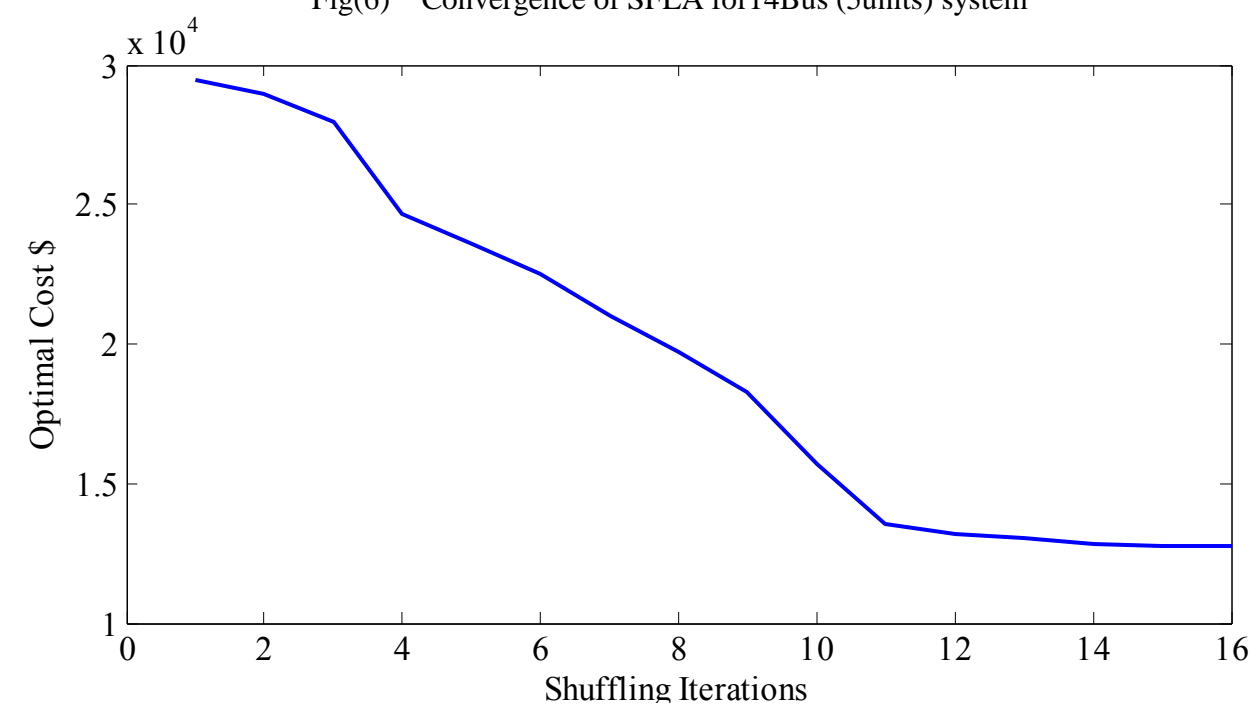

Fig(7) Convergence of SFLA for 30 Bus (6 units) system 


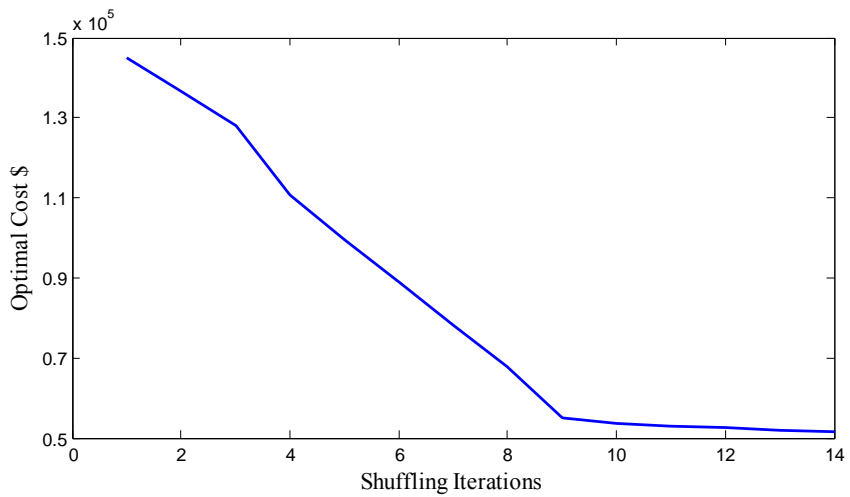

Fig(8) Convergence of SFLA for 56Bus (7 units) system

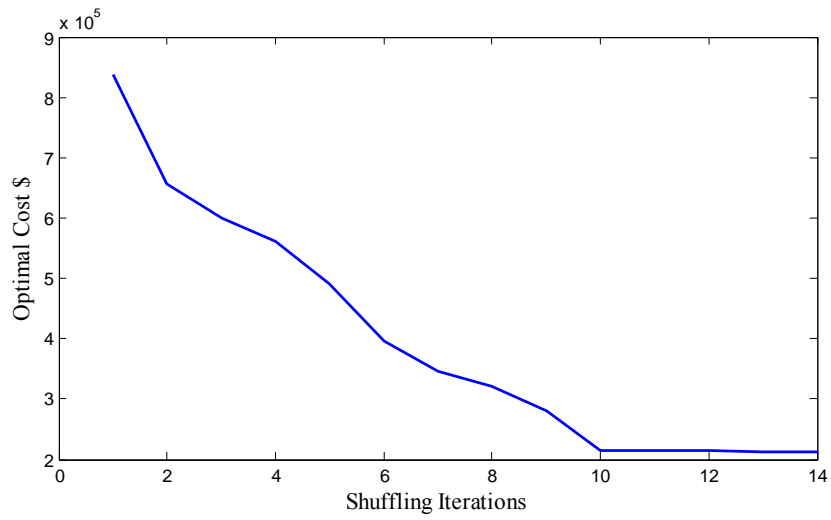

Fig(9) Convergence of SFLA for 118Bus (19 units) system

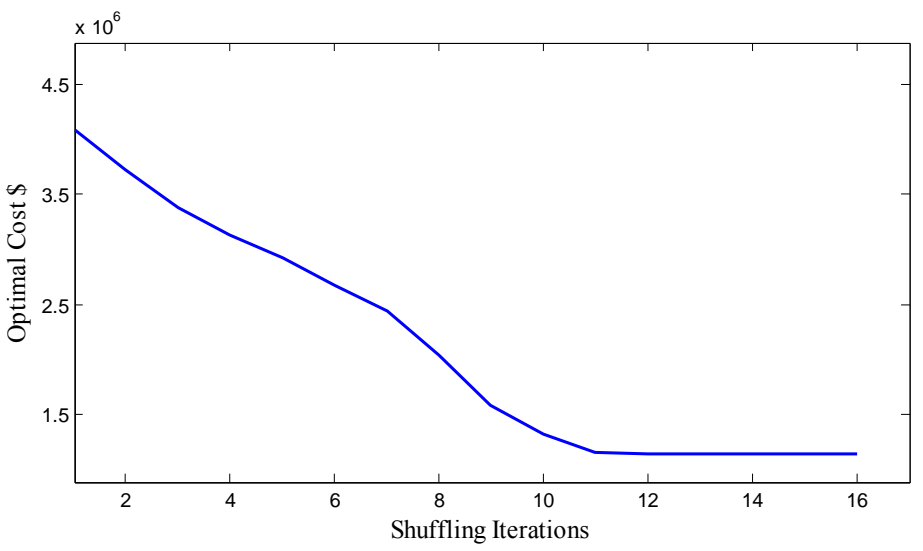

Fig(10) Convergence of SFLA for 10 Unit System

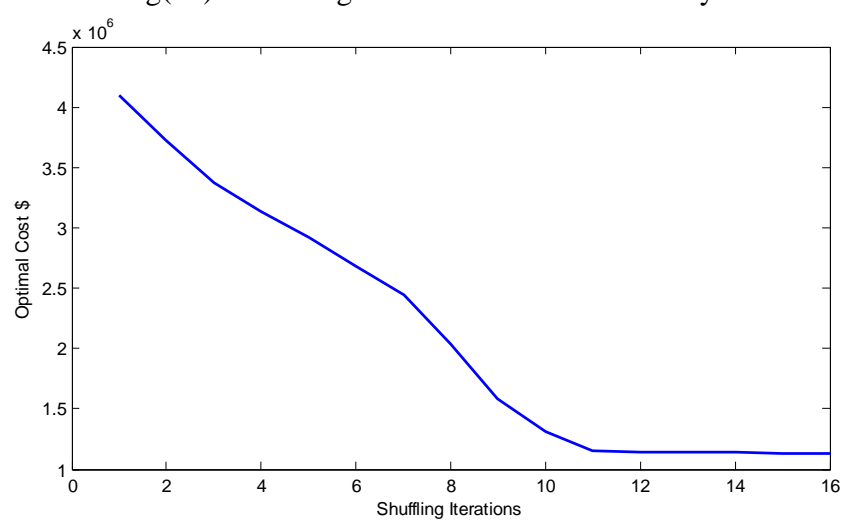

Fig(11) Convergence of SFLA for 20 Unit System www.iosrjournals.org 
TABLE 14

OPTIMAL COST OF BEST RESULT OBTAINED USING SFLA

\begin{tabular}{|c|c|c|l|}
\hline Sl.No & System & $\begin{array}{c}\text { No.of } \\
\text { generating } \\
\text { Units }\end{array}$ & $\begin{array}{c}\text { Optimal Cost(\$) } \\
\text { SFLA }\end{array}$ \\
\hline 1 & IEEE14BUS & 5 & 11171 \\
\hline 2 & IEEE30BUS & 6 & 12768 \\
\hline 3 & IEEE56BUS & 7 & 51645 \\
\hline 4 & IEEE118BUS & 19 & 211810 \\
\hline 5 & 10 UNIT & 10 & 564769 \\
\hline 6 & 20 UNIT & 20 & 1135800 \\
\hline
\end{tabular}

TABLE 15

NO., OF SHUFFLING ITERATIONS TAKEN TO OBTAIN THE BEST RESULT USING SFLA

\begin{tabular}{|c|c|c|c|}
\hline Sl.No & System & $\begin{array}{c}\text { No.of } \\
\text { generating } \\
\text { Units }\end{array}$ & $\begin{array}{c}\text { No., of Shuffling } \\
\text { iterations }\end{array}$ \\
\hline 1 & IEEE14BUS & 5 & 12 \\
\hline 2 & IEEE30BUS & 6 & 16 \\
\hline 3 & IEEE56BUS & 7 & 14 \\
\hline 4 & IEEE118BUS & 19 & 14 \\
\hline 5 & 10 UNIT & 10 & 16 \\
\hline 6 & 20 UNIT & 20 & 16 \\
\hline
\end{tabular}

TABLE 16

COMPARISON OF OPERATION COST OF VARIOUS METHODS

\begin{tabular}{|c|l|l|l|}
\hline \multirow{2}{*}{ No. of Units } & \multicolumn{3}{|c|}{ Operational Cost (\$) } \\
\cline { 2 - 4 } & LRGA & IGCA & SFLA \\
\hline 10 & 565825 & 566404 & 564769 \\
\hline 20 & 1130660 & 1124892 & 1135800 \\
\hline
\end{tabular}

The commitment schedule of generators for various IEEE systems such as 14Bus (5 Units), $30 \mathrm{Bus}$ (6 Units), 56Bus (7 Units), 118 bus (19 Units), 10 Unit system, 20 Units system are tabulated in Table 2 to 7.The results of generation scheduling along with their real power generation of the best solution for 14Bus (5 Units), 30Bus (6 Units), 56Bus ( 7 Units), 118Bus(19 Units), 10 Unit system, 20 Units system are tabulated in Table 8 to 13 . Table 14 gives the optimal cost of the best result obtained after several trials for all test systems. Table 15 gives the no., of shuffling iterations taken to obtain the best result. The optimal solution for all test systems is obtained between 12 to 16 shuffling iterations. The results of SFLA for 10, 20 unit systems are compared with the results of LRGA [7], ICGA [10] and is listed in Table 16. It is obvious that SFLA has satisfactory results in comparison with other methods. Fig. 6 to 11 shows the convergence rate of SFLA for the various systems considered in this work.

\section{CONCLUSION}

In this paper, we presented a new evolutionary algorithm known as SFLA for UC problem. The integer coding is used to code the parameters of UCP. This type of coding directly satisfies the min up/down time constraints, and no need for any penalty function for this constraint. The performance of the proposed algorithm is tested for a one day scheduling and the results compared with LR \& ICGA method. The simulation results show that the production cost of SFLA is less than the other methods such as LR \& ICGA. 


\section{REFERENCES}

[1] A. J. Wood and B. F. Wollenberg(1984), Power Generation Operation and Control, New York: Wiley

[2] D.P. Kothari and J.S.Dhillon(2011), "Power System Optimization”, Prentice Hall of India Pvt. Ltd., New Delhi.

[3] D.P.Kothari and I.J.Nagrath(2011), "Modern Power System Analysis", 4th Edition, McGraw Hill, New York.

[4] N.P. Padhy(2004), "Unit commitment- A Bibliography Survey," IEEE Trans. Power Systems, vol.19,no. 2, pp 11961205, May 2004

[5] W.L. Snyder, H.D. Powell, and J.C. Rayburn(1987), "Dynamic Programming Approach to Unit Commitment", IEEE Trans. Power Systems, vol.2, no. 2,pp.339-347, May 1987.

[6] S.Virmani, E.C. Adrian, K.Imhof(1989), "Implementation of a Lagrangian based Unit Commitment Problem", IEEE Trans. Power Systems,vol.4, no.4,pp 1373-1380, Nov.1989.

[7] S.A.Kazarlis, A.G.Bakitris, and V.Petridis(1996), " A Genetic Algorithm Solution to the Unit Commitment Problem”, IEEE Trans. Power Systems, vol.11,no. 1, pp 83-92, Feb,1996.

[8] K.S.Swarup and S.Yamashiro(2002), "Unit Commitment Solution Methodology using Genetic Algorithm", IEEE Trans. Power Systems, vol.17,no. 1, pp.87-91., Feb 2002.

[9] J.M.Arroyo and A.J.Conejo(2002), "A Parallel Repair Genetic Algorithm to Solve Unit Commitment Problem", IEEE Trans. Power Systems, vol.17, no. 4, pp.1216-1224, Nov 2002.

[10] I.G. Damousis, A.G. Bakirtzis,and P.S. Dokopolous(2004)," A Solution to Unit Commitment Problem using Integer Coded Genetic Algorithm”, IEEE Trans. Power Systems, vol.19,no. 2, pp.1165-1172, May 2004.

[11] W.Xiong, M.J.Li, and Y.Cheng(2008), “An Improved Particle Swarm Optimization Algorithm for Unit Commitment Problem", in Proc. ICICTA, 2008.

[12] Javad Ebrahimi, Seyed Hossein Hosseinain, Gevorg B. Harehpatian(2011), "Unit Commitment Problem Solution Using Shuffled Frog Leaping Algorithm”, IEEE Trans. Power Systems, vol.26, no.2, pp.573-581,May 2011.

[13] M.Eslamian, As.Ah.ahosseinian, B.vahidi(2009), "Bacterial Foraging based Solution to the Unit Commitment Problem," IEEE Trans. Power Systems,vol.24, no. 3, pp.1478-1488, Aug 2009.

[14] M.M.Eusuff,K.E.Lansey, F.Pasha(2006), "Shuffled Frog leaping: A Memetic Meta-Heuristic for Discrete Optimization,” Eng Optimiz, vol.38,no.2,pp.129-154, 2006

[15] X.Zhang, X.Hu,G.Cui, Y.Wang, Y.Niu(2008), “ An Improved Shuffled Frog Leaping Algorithm With Cognitive Behavior," in Proc., $7^{\text {th }}$ World Congress, Intelligent Control and Automation, 2008.

[16] T.H. Huyuth(2008), "A Modified Shuffled Frog Leaping Algorithm for Optimal Tuning of Multivariable PID Controllers," in proc., ICIT 2008, pp 1-6, 2008.

[17] J.Kennedy and R.C. Eberhart(1995), "Particle Swarm Optimization," in Proc, IEEE Conf. Neural Networks, 1995, vol.4, pp.1942-1948.

\section{APPENDIX: A}

Load Data for all test systems

\begin{tabular}{|c|c|c|c|c|c|c|c|c|c|c|c|c|c|}
\hline Hour & System & 1 & 2 & 3 & 4 & 5 & 6 & 7 & 8 & 9 & 10 & 11 & 12 \\
\hline \multirow{6}{*}{ Load (MW) } & 14Bus & 148 & 173 & 220 & 244 & 259 & 248 & 227 & 202 & 176 & 134 & 100 & 130 \\
\hline & 30Bus & 166 & 196 & 229 & 267 & 283.4 & 272 & 246 & 213 & 192 & 161 & 147 & 160 \\
\hline & 56Bus & 540 & 620 & 954 & 1026 & 1002 & 992 & 978 & 956 & 942 & 922 & 902 & 751 \\
\hline & $75 \mathrm{Bus}$ & 3352 & 3384 & 3437 & 3489 & 3659 & 3849 & 3898 & 3849 & 3764 & 3637 & 3437 & 3384 \\
\hline & 118Bus & 3170 & 3200 & 3250 & 3300 & 3460 & 3640 & 3686 & 3640 & 3560 & 3440 & 3250 & 3200 \\
\hline & $10 \mathrm{Un}$ it & 700 & 750 & 850 & 950 & 1000 & 1100 & 1150 & 1200 & 1300 & 1400 & 1450 & 1500 \\
\hline Hour & System & 13 & 14 & 15 & 16 & 17 & 18 & 19 & 20 & 21 & 22 & 23 & 24 \\
\hline \multirow{6}{*}{ Load(MW) } & 14Bus & 157 & 168 & 195 & 225 & 244 & 241 & 230 & 210 & 176 & 157 & 138 & 103 \\
\hline & 30Bus & 170 & 185 & 208 & 232 & 246 & 241 & 236 & 225 & 204 & 182 & 161 & 131 \\
\hline & 56Bus & 651 & 588 & 602 & 768 & 876 & 863 & 843 & 802 & 784 & 702 & 692 & 645 \\
\hline & $75 \mathrm{Bus}$ & 3357 & 3394 & 3616 & 3828 & 3828 & 3786 & 3659 & 3458 & 3394 & 3334 & 3329 & 3348 \\
\hline & 118Bus & 3175 & 3210 & 3420 & 3620 & 3620 & 3580 & 3460 & 3270 & 3210 & 3153 & 3148 & 3166 \\
\hline & $10 \mathrm{Un}$ it & 1400 & 1300 & 1200 & 1050 & 1000 & 1100 & 1200 & 1400 & 1300 & 1100 & 900 & 800 \\
\hline
\end{tabular}

\section{APPENDIX: B}

14 BUS (5 UNIT) SYSTEM DATA

\begin{tabular}{|c|c|c|c|c|c|c|c|c|c|c|c|}
\hline & Pmax & Pmin & A & B & C & MUi & MDi & Hcost & Ccost & Chour & IniState \\
\hline Unit1 & 250 & 10 & 0.00315 & 2.0 & 0 & 1 & 1 & 70 & 176 & 2 & 1 \\
\hline Unit2 & 140 & 20 & 0.01750 & 1.75 & 0 & 2 & 1 & 74 & 187 & 2 & -3 \\
\hline Unit3 & 100 & 15 & 0.06250 & 1.0 & 0 & 1 & 1 & 50 & 113 & 1 & -2 \\
\hline Unit4 & 120 & 10 & 0.00834 & 3.25 & 0 & 2 & 2 & 110 & 267 & 1 & -3 \\
\hline Unit5 & 45 & 10 & 0.0250 & 3.0 & 0 & 1 & 1 & 72 & 180 & 1 & -2 \\
\hline
\end{tabular}


30 BUS (6 UNIT) SYSTEM DATA

\begin{tabular}{|c|c|c|c|c|c|c|c|c|c|c|c|}
\hline & Pmax & Pmin & A & B & C & MUi & MDi & Hcost & Ccost & Chour & IniState \\
\hline Unit1 & 200 & 50 & 0.00375 & 2.0 & 0 & 1 & 1 & 70 & 176 & 2 & 1 \\
\hline Unit2 & 80 & 20 & 0.01750 & 1.70 & 0 & 2 & 2 & 74 & 187 & 1 & -3 \\
\hline Unit3 & 50 & 15 & 0.06250 & 1.0 & 0 & 1 & 1 & 50 & 113 & 1 & -2 \\
\hline Unit4 & 35 & 10 & 0.00834 & 3.25 & 0 & 1 & 2 & 110 & 267 & 1 & -3 \\
\hline Unit5 & 30 & 10 & 0.0250 & 3.0 & 0 & 2 & 1 & 72 & 180 & 1 & -2 \\
\hline Unit6 & 40 & 12 & 0.0250 & 3.0 & 0 & 1 & 1 & 40 & 113 & 1 & -2 \\
\hline
\end{tabular}

56 BUS (7 UNIT) SYSTEM DATA

\begin{tabular}{|c|c|c|c|c|c|c|c|c|c|c|c|}
\hline & Pmax & Pmin & A & B & C & MUi & MDi & Hcost & Ccost & Chour & IniState \\
\hline Unit1 & 576 & 50 & 0.001736 & 1.73647 & 0 & 3 & 2 & 70 & 176 & 3 & 4 \\
\hline Unit2 & 100 & 10 & 0.01000 & 10.0000 & 0 & 2 & 1 & 74 & 187 & 2 & 5 \\
\hline Unit3 & 140 & 20 & 0.007143 & 7.14286 & 0 & 3 & 1 & 50 & 113 & 3 & 5 \\
\hline Unit4 & 100 & 10 & 0.01000 & 10.0000 & 0 & 4 & 2 & 110 & 267 & 1 & 7 \\
\hline Unit5 & 550 & 40 & 0.001818 & 1.81818 & 0 & 1 & 1 & 72 & 180 & 1 & 5 \\
\hline Unit6 & 100 & 10 & 0.01000 & 10.0000 & 0 & 1 & 3 & 40 & 113 & 1 & 3 \\
\hline Unit7 & 410 & 30 & 0.002439 & 2.43902 & 0 & 2 & 1 & 70 & 176 & 2 & 4 \\
\hline
\end{tabular}

118 BUS (19 UNIT) SYSTEM DATA

\begin{tabular}{|c|c|c|c|c|c|c|c|c|c|c|c|}
\hline & Pmax & Pmin & A & B & C & MUi & MDi & Hcost & Ccost & Chour & IniState \\
\hline Unit1 & 500 & 50 & 0.0018 & 1.818 & 0 & 3 & 2 & 70 & 176 & 3 & 4 \\
\hline Unit2 & 90 & 10 & 0.0054 & 5.405 & 0 & 3 & 1 & 74 & 187 & 2 & -5 \\
\hline Unit3 & 300 & 30 & 0.0031 & 3.125 & 0 & 3 & 2 & 50 & 113 & 3 & -5 \\
\hline Unit4 & 400 & 40 & 0.0024 & 2.415 & 0 & 4 & 2 & 110 & 267 & 1 & 7 \\
\hline Unit5 & 10 & 1 & 0.0093 & 9.346 & 0 & 1 & 1 & 72 & 180 & 1 & -5 \\
\hline Unit6 & 23 & 3 & 0.0084 & 8.403 & 0 & 1 & 1 & 40 & 113 & 1 & -3 \\
\hline Unit7 & 240 & 30 & 0.0033 & 3.289 & 0 & 2 & 1 & 70 & 176 & 2 & -4 \\
\hline Unit8 & 50 & 5 & 0.0068 & 6.757 & 0 & 3 & 1 & 74 & 187 & 1 & -5 \\
\hline Unit9 & 200 & 20 & 0.0039 & 3.922 & 0 & 4 & 5 & 50 & 113 & 3 & -5 \\
\hline Unit10 & 200 & 20 & 0.0038 & 3.846 & 0 & 2 & 1 & 110 & 267 & 1 & -7 \\
\hline Unit11 & 400 & 90 & 0.0020 & 2.037 & 0 & 3 & 2 & 72 & 180 & 2 & -5 \\
\hline Unit12 & 400 & 90 & 0.0020 & 2.032 & 0 & 3 & 1 & 40 & 113 & 1 & -3 \\
\hline Unit13 & 900 & 100 & 0.0012 & 1.242 & 0 & 3 & 2 & 70 & 176 & 2 & 10 \\
\hline Unit14 & 600 & 50 & 0.0017 & 1.733 & 0 & 2 & 1 & 74 & 187 & 1 & -5 \\
\hline Unit15 & 5 & 1 & 0.0096 & 9.615 & 0 & 1 & 1 & 50 & 113 & 0 & -5 \\
\hline Unit16 & 700 & 50 & 0.0014 & 1.414 & 0 & 2 & 2 & 110 & 267 & 1 & 7 \\
\hline Unit17 & 300 & 30 & 0.0028 & 2.841 & 0 & 3 & 1 & 72 & 180 & 2 & -5 \\
\hline Unit18 & 50 & 5 & 0.0071 & 7.143 & 0 & 3 & 1 & 40 & 113 & 1 & -3 \\
\hline Unit19 & 40 & 4 & 0.0074 & 7.353 & 0 & 1 & 1 & 70 & 176 & 0 & -4 \\
\hline
\end{tabular}

10 UNIT SYSTEM DATA

\begin{tabular}{|c|c|c|c|c|c|c|c|c|c|c|c|}
\hline & Pmax & Pmin & A & B & C & MUi & MDi & Hcost & Ccost & Chour & IniState \\
\hline Unit1 & 455 & 150 & 0.00048 & 16.19 & 1000 & 8 & 8 & 4500 & 9000 & 5 & 8 \\
\hline Unit2 & 455 & 150 & 0.00031 & 17.26 & 970 & 8 & 8 & 5000 & 10000 & 5 & 8 \\
\hline Unit3 & 130 & 20 & 0.002 & 16.60 & 700 & 5 & 5 & 550 & 1100 & 4 & -5 \\
\hline Unit4 & 130 & 20 & 0.00211 & 16.5 & 680 & 5 & 5 & 560 & 1120 & 4 & -5 \\
\hline Unit5 & 162 & 25 & 0.00398 & 19.70 & 450 & 6 & 6 & 900 & 1800 & 4 & -6 \\
\hline Unit6 & 80 & 20 & 0.00712 & 22.26 & 370 & 3 & 3 & 170 & 340 & 2 & -3 \\
\hline Unit7 & 85 & 25 & 0.00079 & 27.74 & 480 & 3 & 3 & 260 & 520 & 2 & -3 \\
\hline Unit8 & 55 & 10 & 0.00413 & 25.92 & 660 & 1 & 1 & 30 & 60 & 0 & -1 \\
\hline Unit9 & 55 & 10 & 0.00222 & 27.27 & 665 & 1 & 1 & 30 & 60 & 0 & -1 \\
\hline Unit10 & 55 & 10 & 0.00173 & 27.79 & 670 & 1 & 1 & 30 & 60 & 0 & -1 \\
\hline
\end{tabular}

